\title{
Comparison of Passive Intermodulation Measurements for the U.S. Wireless Industry
}

Jeffrey A. Jargon Donald C. DeGroot

QC

100

.45753

N0. 1515

1999 



\section{Comparison of Passive Intermodulation Measurements for the U.S. Wireless Industry}

Jeffrey A. Jargon

Donald C. DeGroot

Radio-Frequency Technology Division

Electronics and Electrical Engineering Laboratory

National Institute of Standards and Technology

325 Broadway

Boulder, Colorado 80303-3328

October 1999

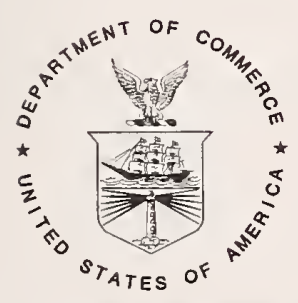

U.S. DEPARTMENT OF COMMERCE, William M. Daley, Secretary TECHNOLOGY ADMINISTRATION, Gary R. Bachula, Acting Under Secretary for Technology NATIONAL INSTITUTE OF STANDARDS AND TECHNOLOGY, Raymond G. Kammer, Director 
National Institute of Standards and Technology Technical Note Natl. Inst. Stand. Technol., Tech. Note 1515, 48 pages (October 1999) CODEN:NTNOEF

\section{U.S. GOVERNMENT PRINTING OFFICE \\ WASHINGTON: 1999}

For sale by the Superintendent of Documents, U.S. Government Printing Office, Washington, DC 20402-9325 


\section{Contents}

1. Introduction 2

2. Motivations 3

3. Methodology 4

4. Results 6

4.1. AMPS Band 6

$\begin{array}{ll}\text { 4.2. GSM Band } & 7\end{array}$

4.3. PCS Band 8

4.4. DCS Band 8

4.5. Long-Term Stability 9

5. Discussion and Conclusions 9

6. Acknowledgments 10

$\begin{array}{ll}\text { 7. References } & 10\end{array}$

Appendix A. Instructions for Participants $\quad 41$

Appendix B. Artifact Measurement Form 43 



\title{
Comparison of Passive Intermodulation Measurements for the U.S. Wireless Industry
}

\author{
Jeffrey A. Jargon \& Donald C. DeGroot \\ National Institute of Standards and Technology \\ Radio-Frequency Technology Division
}

In response to requests by U.S. industry and members of the International Electrotechnical Commission, the National Institute of Standards and Technology initiated a comparison of measurements of passive intermodulation for the U.S. wireless industry. The goal of this comparison was to determine the level of agreement in measurements of passive intermodulation (PIM) made by U.S. manufacturers and suppliers of passive components for wireless-communication base stations. This study reveals not only the difficulties industry is having in making PIM measurements, but also provides U.S. companies with a tool to improve their measurement capabilities as they deal with PIM-related trade barriers. Since August of 1998, ten U.S. companies have participated in the PIM intercomparison. The participants measured four round-robin artifacts and contributed 19 data sets for four different commercial communications bands. This report preserves company anonymity, and allows participants to determine how well their measurements compare to ensemble averages for each of the four artifacts in each of four communication bands. While the study shows the majority of participants reporting PIM levels within one standard deviation of the mean values, it also reveals significant discrepancies reported by some.

Key Words: communications, comparison, intermodulation, measurement, passive, thirdorder, wireless. 


\section{Introduction}

Passive intermodulation (PIM) is a form of signal distortion that occurs whenever signals at two or more frequencies conduct simultaneously in a passive device, such as a cable or connector, which contains some nonlinear response. The non-linear behavior produces spurious signals whose frequencies are linear combinations of the frequencies of the original signals. The lower odd-ordered intermodulation (IM) products (e.g. $f(I M 3)=2 f_{1}-f_{2}$ ) are usually the most problematic in the wireless industry since they have the highest potential of falling within the receive band, or up-link, of a base station, creating if interference in the receiver [1]. Although frequency allocations are specifically designed to guard against this problem, collocation of two or more base station transceivers at a single site substantially increases the risk of PIM interference [2], as illustrated in Figure 1.

Base stations built for mobile communications systems such as Personal Communication Service (PCS 1900), Advance Mobile Phone System (AMPS), Global System for Mobile communications (GSM), and Digital Communications System (DCS 1800), use DIN (Deutsche Industrinorm) 7-16 and Type $\mathrm{N}$ coaxial connectors to handle the high transmit power requirements. At high (above $1 \mathrm{~W}$ ) power, non-linearities in coaxial connectors become apparent and measurable [3]. The many possible causes of intermodulation in coaxial connectors and cables include poor mechanical contact, dissimilar metals in direct contact, ferrous content in the conductors, debris within the connector, poor surface finish, corrosion, vibration, and temperature variations. The sources of PIM have been studied extensively at various laboratories [4-15].

$\begin{array}{ccc}\text { Base Station } & \text { Base Station } & \text { Base Station } \\ \text { Receive } & \text { Transmit } & \text { Transmit }\end{array}$

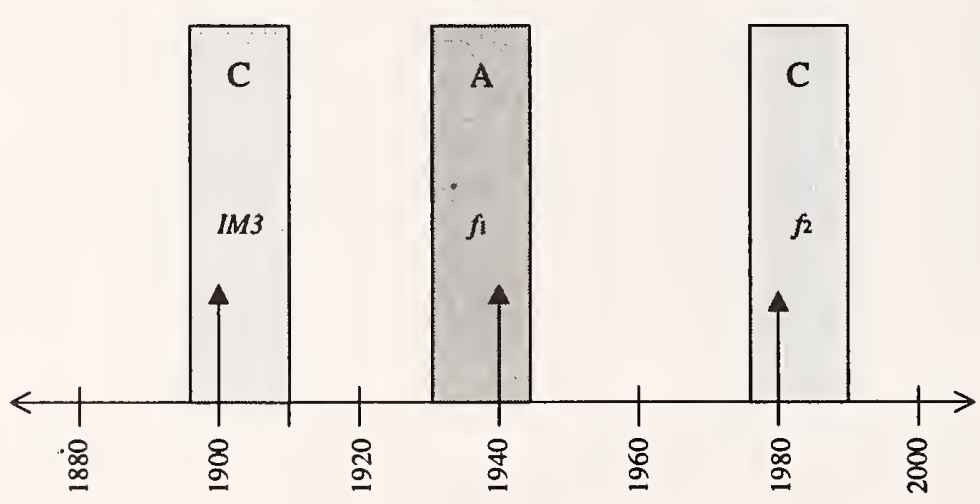

Frequency $(\mathrm{MHz})$

Figure 1. Potential third-order intermodulation in broadband PCS. 


\section{Motivations}

Before beginning the measurement comparison, we had the opportunity to collaborate with members of the Radio-Frequency Fields Group at NIST and a major provider of telecommunications service in measuring passive intermodulation distortion of base-station antennas. Service providers are now interested in measuring PIM of their incoming and field-tested antennas. The new anechoic chamber at NIST allows such measurements to be made with high isolation from external sources generating interference. In addition to measuring numerous antennas, we also looked at a number of other passive devices. One of the experiments performed was to compare two commercial cables used in PCS base stations. The powers of the third-order IM products of each cable were measured using two $\mathrm{cw}$ signal sources each measuring $+40 \mathrm{dBm}(10 \mathrm{~W})$ at the instrument's test port, which is comparable to the power levels they are exposed to in the field. Both cables had DIN 7-16 connectors and were supposedly within PIM specifications $(P(I M 3)<120 \mathrm{dBm})$. Figure 2 shows the results. While one cable clearly met specifications throughout the frequency range, the other one exceeded specifications at all frequencies by more than $30 \mathrm{~dB}$. Thus, our corporate partner concluded that it was important to measure all passive components in a base station that have the potential of causing IM distortion, regardless of manufacturers' specifications.

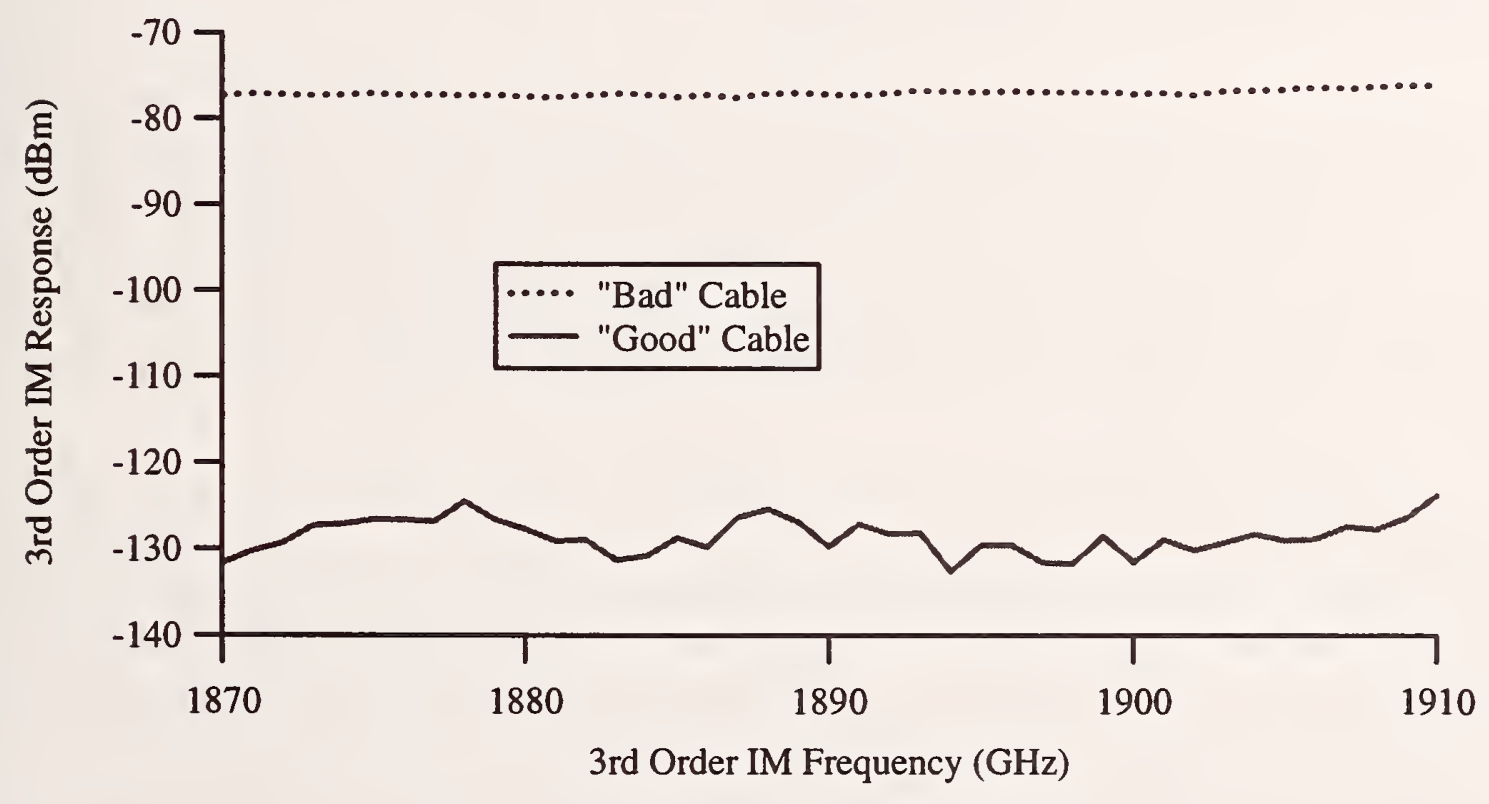

Figure 2. Third-order response of two commercial cables used in PCS base stations. 
Coaxial connectors can be a major source of intermodulation distortion in communications systems. Due to the high transmit power levels required at base stations, the two most widely used connector types are Type N and DIN 7-16. In the United States, the Type $\mathrm{N}$ connector has been widely used for many years, although the DIN 7-16 connector is rapidly becoming the connector of choice by manufacturers of base-station equipment. A previous publication [16] has reported that DIN 7-16 connectors show a measurable improvement in reducing PIM compared to the Type $\mathrm{N}$ connectors. We performed our own measurements on coaxial cables with Type $\mathrm{N}$ connectors using a commercial passive intermodulation analyzer to verify these claims. We applied two continuouswave $(\mathrm{cw})$ signal sources each measuring $+40 \mathrm{dBm}(10 \mathrm{~W})$ at the instrument's test port, much like we did with the DIN 7-16 cables previously, only this time using an AMPS system. We found the third-order $\mathrm{IM}$ products to be in the range of $-70 \mathrm{dBm}$ at most frequencies, more than $10 \mathrm{~dB}$ higher than even the worst DIN 7-16 cable. Thus, we obtained our first evidence of the dramatic difference in PIM levels between the two types of connectors.

\section{Methodology}

To conduct the U.S. PIM comparison, NIST obtained two sets of artifacts, one which was used as control artifacts by NIST, and the other which was circulated among the participating companies. The artifacts were labeled with different colors to distinguish them: red, white, yellow, and blue. Each artifact had two ports with male and female DIN 7-16 connectors and varying passive non-linearities. The red, white, and yellow artifacts were simply male-to-female adapters with diodes inserted through the outer conductor wall to generate non-linearities of varying degrees. The blue artifact, which also had a diode inserted in one connector, was a cable-assembly whose purpose was to create noticeable frequency-dependent behavior.

Following the International Electrotechnical Commission's guidelines [17], the powers of the third-order IM products of each artifact were measured with two $\mathrm{cw}$ signal sources, each measuring $+43 \mathrm{dBm}(20 \mathrm{~W})$ at the test ports. Each artifact was measured within the base station receive (up-link) band of any or all of the four communications bands listed in Table 1, when the two $+43 \mathrm{dBm}$ signals were tuned to fall within the corresponding base-station transmit (down-link) band. The minimum required data from each participant was a single third-order intermodulation power in one communication band.

Participating companies were asked to measure either or both forward and reflected intermodulation products, as illustrated in Figure 3. To measure reflected intermodulation, participants were instructed to connect the male connector of the artifact to the active test port of their system and the female connector of the artifact to a low PIM load. To measure forward intermodulation, they were instructed to connect the male connector of the artifact to the active test port of their system and the female connector of the artifact to their own cable that was in turn connected to the receiving port of their system. Participants who had the ability to make sweptfrequency measurements were encouraged to make additional measurements at specified frequencies. Those who had systems that could measure intermodulation products in more than one 
Table 1. Base station receive and transmit frequencies for four communications bands.

\begin{tabular}{|c|c|c|}
\hline $\begin{array}{c}\text { Communication } \\
\text { band }\end{array}$ & $\begin{array}{c}\text { Base station } \\
\text { receive } \\
\text { frequencies } \\
\text { (up-link) } \\
\text { (MHz) }\end{array}$ & $\begin{array}{c}\text { Base station } \\
\text { transmit } \\
\text { frequencies } \\
\text { (down-link) } \\
\text { (MHz) }\end{array}$ \\
\hline AMPS & $824-849$ & $869-894$ \\
PCS 1900 & $1850-1910$ & $1930-1990$ \\
GSM & $890-915$ & $935-960$ \\
DCS 1800 & $1710-1785$ & $1805-1880$ \\
\hline
\end{tabular}

Reflected

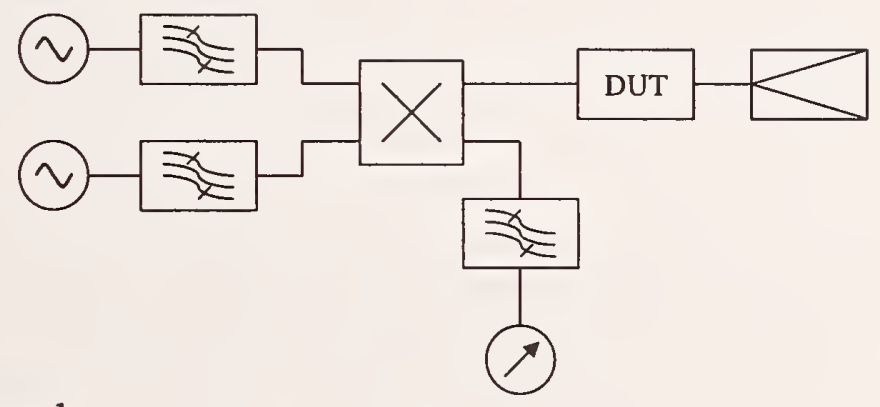

Forward

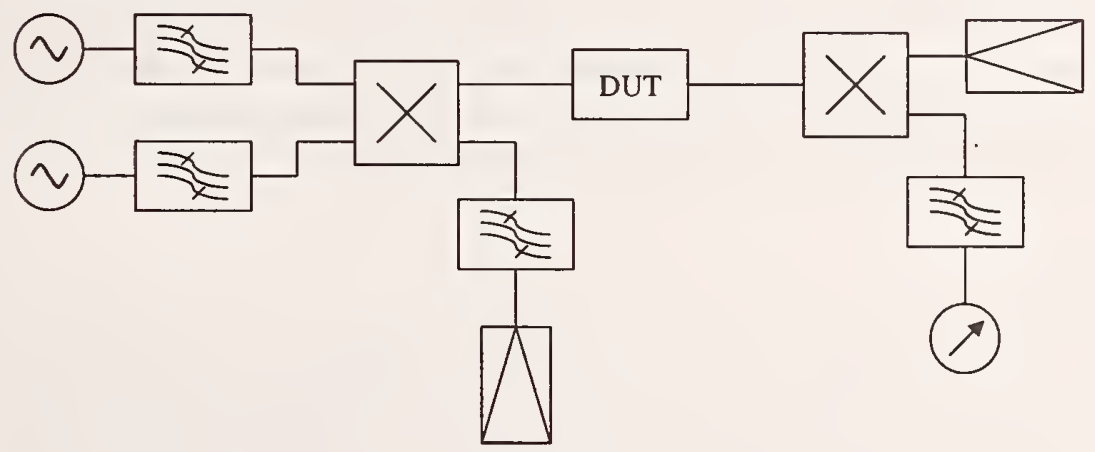

Figure 3. Two configurations for measuring passive intermodulation products: reflected and forward. 
communication band and those who had multiple systems were encouraged to measure the devices in as many different bands as possible. Appendix A contains the Instructions for Participants, and Appendix B includes the Artifact Measurement Form that each participant completed.

The role of NIST in this comparison was to act as a pilot laboratory. Without knowing absolute PIM values, our tasks were to organize the comparison, measure the stability throughout the study, keep a database of the measurements, and report the results [18]. Our first responsibility was to procure a passive IM analyzer and two sets of artifacts, one of which we kept in-house for measuring the long-term stability of our system, and the other of which we circulated among the participants. After each company measured the set of four artifacts, they sent them back to us, along with their data, and we re-measured the artifacts to ensure that they were still in working order, before sending them to the next company. Now that 10 companies have contributed 19 data sets over the past 9 months, we present a report showing how each of the participants' measurements compare with the ensemble, keeping all companies' identities confidential.

\section{Results}

Of the 10 participants, 5 made measurements in the AMPS band, 6 in the GSM band, 6 in the PCS band, and 2 in the DCS band. The data presented in this report span a time period of 9 months - the first participant made measurements in August 1998 and the tenth participant in April 1999.

Tables 2 through 23 list the measured data, along with mean values and standard deviations, taken by the 10 participants for each of the 4 round-robin artifacts. These data are also plotted in Figures 4 through 19, where hollow symbols denote reflected measurements, solid shapes denote forward measurements, solid lines between measurements indicate a sweep with source 1 held constant, and dashed lines between measurements indicate a sweep with source 2 held constant. The mean value at each frequency was calculated by converting each of the measured PIM levels from $\mathrm{dBm}$ to watts before computing the mean, and then converting back to $\mathrm{dBm}$. Likewise, the standard deviation at each point was first computed in watts and then converted to $\mathrm{dB}$. Below, we discuss the results obtained in each of the four communications bands.

\subsection{AMPS Band}

We specified five particular IM3 frequencies $(844,845,846,847$, and $848 \mathrm{MHz})$ for measurements spanning the AMPS band. Measurements at these frequencies could be obtained in two ways: (1) holding source 1 at $869 \mathrm{MHz}$ and sweeping source 2 downward from $894 \mathrm{MHz}$ to 890 $\mathrm{MHz}$ in steps of $1 \mathrm{MHz}$, or (2) holding source 2 at $894 \mathrm{MHz}$ and sweeping source 1 upward from $869 \mathrm{MHz}$ to $871 \mathrm{MHz}$ in steps of $0.5 \mathrm{MHz}$. All five participants who made measurements in the AMPS band made swept-frequency measurements in both directions. Participant A made reflected measurements, participant $\mathrm{E}$ made forward measurements, and participants $\mathrm{B}, \mathrm{G}$, and I made both forward and reflected measurements. Tables 2 through 5 list the measured data taken by the five participants for each of the four round-robin artifacts, and Tables 6 and 7 list the mean values and 
standard deviations for each of the artifacts at the five measured frequencies. These data are also plotted in Figures 4 through 7.

From the data we compiled in all of the bands, including AMPS, it appears that there is no significant difference between reflected and forward measurements for the electrically short artifacts (red, white, and yellow). However, there were noticeable differences for the electrically long (blue) artifact, so we separated the two types of measurements when we calculated the mean values and standard deviations. We also found the white artifact to be less stable than the other artifacts in all bands, but could not explain why, since its values of passive intermodulation were very close in value to those of the red artifact. The mean values measured throughout the AMPS band for the red artifact varied between $-100.3 \mathrm{dBm}$ and $-101.4 \mathrm{dBm}$, with standard deviations ranging from $1.5 \mathrm{~dB}$ to $1.9 \mathrm{~dB}$; the mean values of the white artifact varied between $-98.8 \mathrm{dBm}$ and $-99.5 \mathrm{dBm}$, with standard deviations from $2.8 \mathrm{~dB}$ to $4.8 \mathrm{~dB}$; the mean values of the yellow artifact varied between $79.4 \mathrm{dBm}$ and $-79.7 \mathrm{dBm}$, with standard deviations from $1.3 \mathrm{~dB}$ to $1.9 \mathrm{~dB}$; the mean values of the blue artifact measured in the reflected configuration, varied between $-93.6 \mathrm{dBm}$ and $-95.1 \mathrm{dBm}$, with standard deviations from 3.3 to $4.6 \mathrm{~dB}$; and the mean values of the blue artifact measured in the forward configuration, varied between $-87.9 \mathrm{dBm}$ and $-88.3 \mathrm{dBm}$, with standard deviations from 1.4 $\mathrm{dB}$ to $2.1 \mathrm{~dB}$.

\subsection{GSM Band}

We specified five particular IM3 frequencies $(890,895,900,905$, and $910 \mathrm{MHz}$ ) for measurements spanning the GSM band. Measurements at these frequencies could be obtained in two ways: (1) holding source 1 at $925 \mathrm{MHz}$ and sweeping source 2 downward from $960 \mathrm{MHz}$ to 940 $\mathrm{MHz}$ in steps of $5 \mathrm{MHz}$, or (2) holding source 2 at $960 \mathrm{MHz}$ and sweeping source 1 upward from $925 \mathrm{MHz}$ to $935 \mathrm{MHz}$ in steps of $2.5 \mathrm{MHz}$. Of the six participants who made measurements in the GSM band, two made swept-frequency measurements. The other four made measurements at 910 $\mathrm{MHz}$ (source 1 at $935 \mathrm{MHz}$ and source 2 at $960 \mathrm{MHz}$ ). Participants B, F, and $\mathrm{J}$ made reflected measurements, participant $\mathrm{D}$ made forward measurements, and participants $\mathrm{C}$ and $\mathrm{H}$ made both forward and reflected measurements. Tables 8 through 11 list the measured data taken by the five participants for each of the four round-robin artifacts, and Tables 12 and 13 list the mean values and standard deviations for each of the artifacts at $910 \mathrm{MHz}$. These data are also plotted in Figures 8 through 11 .

Similar to the AMPS band comparison, the GSM measurements showed no difference between reflected and forward measurements for the electrically short artifacts (red, white, and yellow) but did for the electrically long (blue) artifact. And once again, we found the white artifact to be less repeatable than the others. Since only two participants made swept-frequency measurements in the GSM band, we performed statistical calculations only for $910 \mathrm{MHz}$, where all of the participants made measurements. Participant D's measurements were more than $30 \mathrm{~dB}$ lower than the others' for all four artifacts, so we did not include their data in the figures or the computations of mean values and standard deviations. For the remaining five participants, the mean value measured at $910 \mathrm{MHz}$ in the GSM band for the red artifact was $-102.3 \mathrm{dBm}$, with a standard deviation of $2.3 \mathrm{~dB}$; the mean of the white artifact was $-99.9 \mathrm{dBm}$, with a standard deviation of 3.6 
$\mathrm{dB}$; the mean of the yellow artifact was $-80.1 \mathrm{dBm}$, with a standard deviation of $0.7 \mathrm{~dB}$; the mean of the blue artifact measured in the reflected configuration was $-93.2 \mathrm{dBm}$, with a standard deviation of $1.1 \mathrm{~dB}$; and the mean of the blue artifact measured in the forward configuration was $-88.3 \mathrm{dBm}$, with standard deviation of $2.6 \mathrm{~dB}$.

\subsection{PCS Band}

We specified five particular IM3 frequencies (1870, 1880, 1890, 1900, and $1910 \mathrm{MHz}$ ) for measurements spanning the PCS band. Measurements at these frequencies could be obtained in two ways: (1) holding source 1 at $1930 \mathrm{MHz}$ and sweeping source 2 downward from $1990 \mathrm{MHz}$ to 1950 $\mathrm{MHz}$ in steps of $10 \mathrm{MHz}$, or (2) holding source 2 at $1990 \mathrm{MHz}$ and sweeping source 1 upward from $1930 \mathrm{MHz}$ to $1950 \mathrm{MHz}$ in steps of $5 \mathrm{MHz}$. Of the six participants who made measurements in the PCS band, five made swept-frequency measurements in both directions, and one made sweptfrequency measurements in one direction (source 1 held constant). Participant B made reflected measurements, participant E made forward measurements, and participants A, F, G, and I made both forward and reflected measurements. Tables 14 through 17 list the measured data taken by the six participants for each of the four round-robin artifacts, and Tables 18 and 19 list the mean values and standard deviations for each of the artifacts at the five measured frequencies. These data are also plotted in Figures 12 through 15.

Overall, measurements in the PCS band showed significantly larger variations than those seen in either the AMPS or GSM bands, which is consistent with the results of the European roundrobin [19]. Similar to the AMPS and GSM comparisons, the PCS measurements showed no difference between reflected and forward measurements for the electrically short artifacts (red, white, and yellow) but did for the electrically long (blue) artifact. We observed frequency-dependent behavior in the blue artifact when reflected measurements were made, which is predicted by models developed by Deats and Hartman [20] and Jargon et al. [18]. This is not to say that the blue artifact is not frequency dependent at lower frequencies, but rather the frequency range of the PCS band is much wider than both the AMPS and GSM bands. Thus, the frequency-dependent behavior is more apparent in PCS when swept-frequency, reflected measurements are performed. And once again, we found the white artifact to be less stable than the others. The mean values measured throughout the PCS band for the red artifact varied between $-98.9 \mathrm{dBm}$ and $-100.6 \mathrm{dBm}$, with standard deviations ranging from $2.3 \mathrm{~dB}$ to $7.4 \mathrm{~dB}$; the mean values of the white artifact varied between $-87.9 \mathrm{dBm}$ and $-90.5 \mathrm{dBm}$, with standard deviations from $7.5 \mathrm{~dB}$ to $8.0 \mathrm{~dB}$; the mean values of the yellow artifact varied between $-73.7 \mathrm{dBm}$ and $-74.4 \mathrm{dBm}$, with standard deviations from $3.5 \mathrm{~dB}$ to $4.8 \mathrm{~dB}$; the mean values of the blue artifact measured in the reflected configuration showed a downward trend in PIM from $-83.5 \mathrm{dBm}$ at $1870 \mathrm{MHz}$ to $-95.1 \mathrm{dBm}$ at $1910 \mathrm{MHz}$, with standard deviations from 2.5 to 3.7 $\mathrm{dB}$; and the mean values of the blue artifact measured in the forward configuration varied between $-84.3 \mathrm{dBm}$ and $-85.7 \mathrm{dBm}$, with standard deviations from $2.5 \mathrm{~dB}$ to $3.2 \mathrm{~dB}$.

\subsection{DCS Band}

We specified five particular IM3 frequencies (1730, 1740, 1750, 1760, and $1770 \mathrm{MHz})$ for measurements spanning the DCS band. Measurements at these frequencies could be obtained in two 
ways: (1) holding source 1 at $1805 \mathrm{MHz}$ and sweeping source 2 downward from $1880 \mathrm{MHz}$ to 1840 $\mathrm{MHz}$ in steps of $10 \mathrm{MHz}$, or (2) holding source 2 at $1880 \mathrm{MHz}$ and sweeping source 1 upward from $1805 \mathrm{MHz}$ to $1825 \mathrm{MHz}$ in steps of $5 \mathrm{MHz}$. Participants B and J made measurements in the DCS band. Participant B performed both forward and reflected measurements, and participant $\mathrm{J}$ made reflected measurements. Tables 20-23 list the measured data taken by the participants for each of the four round-robin artifacts. These data are also plotted in Figures 16-19.

Since only two participants made measurements in the DCS band, we did not perform any statistical computations. However, similar to the PCS band, we did observe frequency-dependent behavior in the blue artifact when reflected measurements were made. And once again, we attribute this to the wide bandwidth of the DCS band.

\subsection{Long-Term Stability}

For the first four months of the comparison (August through November 1998), we made stability-check measurements on an AMPS system, and then for the remainder of the comparison (November 1998 through April 1999), we have made measurements on a PCS system. We also procured two sets of artifacts. One set of artifacts has been circulated among the participants, and the other set has been kept in-house to verify the long-term stability of our systems. In the event that our system shows large variations in the round-robin artifacts, we can use the in-house artifacts to determine whether the problem is due to the artifacts themselves varying or whether something was wrong with the system. Fortunately, this has not happened yet. Our systems and the round-robin artifacts have remained stable throughout the comparison. Table 24 lists the standard deviations of the measurements made at NIST of the round-robin artifacts. All of the artifacts have remained stable within standard deviations of $2.9 \mathrm{~dB}$ or less for up to five months on a single system.

\section{Discussion and Conclusions}

Of the 19 data sets received, most companies' measurements fell within 2 standard deviations of the measured means of each band. In the AMPS band, 3 of the 5 participants' measurements fell consistently outside 1 standard deviation (typically less than $3 \mathrm{~dB}$ ), although all the measurements fell within 3 standard deviations. In the GSM band, only 2 of the 6 participants' measurements fell consistently outside 1 standard deviation (typically less than $3 \mathrm{~dB}$ ), and all were within 2 standard deviations, except for one, which was as much as $50 \mathrm{~dB}$ from the mean. In the PCS band, none of the 6 participants measured consistently outside 1 standard deviation (between $2 \mathrm{~dB}$ and $8 \mathrm{~dB}$ ), except for measurements of the yellow artifact, where 2 participants measured outside 3 standard deviations from the mean.

We make several conclusions with regard to PIM measurements. First of all, it appears that there is no significant difference between reflected and forward measurements for electrically short artifacts (red, white, and yellow). However, there were noticeable differences for the electrically long (blue) artifact. Secondly, intermodulation in passive devices is not always frequency independent. This contradicts the findings of the European round-robin performed in 1995 [4]. Figure 20 plots PIM versus frequency for the red, white, and yellow artifacts. Our white and yellow artifacts show 
deviations by up to $10 \mathrm{~dB}$ between lower frequencies (AMPS and GSM) and higher frequencies (PCS and DCS). We also observed frequency-dependent behavior over a frequency range of $40 \mathrm{MHz}$ in the blue artifact when reflected measurements were made. Measurements in the PCS band showed significantly larger variations than those seen in either the AMPS or GSM bands, due to the higher operating frequencies. This behavior agrees with the findings of the European round-robin. Finally, we found that measurements made by our system of the round-robin artifacts remained stable within a standard deviation of $2.9 \mathrm{~dB}$ over a five-month period.

This comparison of passive intermodulation measurements has addressed, in a timely manner, a direct need expressed to NIST by U.S. base station equipment manufacturers. This comparison allows each participant to assess its capabilities in an impartial way, while also allowing NIST to evaluate the urgency of any PIM measurement problems that may exist within the industry.

\section{Acknowledgments}

The authors thank Werner Wild of Spinner GmbH; Charlie Spellman of RFS Cablewave Systems; Chuck Gilbert of USWest Communications; and Rick Hartman, Brad Deats, and James Brunner of Summitek Instruments.

\section{References}

[1] Nagel, R. and Audenaerde, K., Passive intermodulation in duplexed communication systems, Semint97, Parana, Brazil; Oct. 1997.

[2] Lang, M., The intermodulation problem in mobile communications, Microwave Journal: 20-28; May 1995.

[3] King, J., Intermodulation in coaxial connectors, RF Design: 68-71; Sep. 1996.

[4] Bayrak, M. and Benson, F. A., Intermodulation products from nonlinearities in transmission lines and connectors at microwave frequencies, Proceedings of the IEE 122(4): 361-367; Apr. 1975.

[5] Young, C.E., The danger of intermodulation generation by if connector hardware containing ferromagnetic materials, Naval Research Laboratory Memorandum Report 4233, Presented at the Ninth Annual Connector Symposium: 23-37; Oct. 1976.

[6] Amin, M.B. and Benson, F.A., Nonlinear effects in coaxial cables at microwave frequencies, Electronics Letters 13(25): 768-770; Dec. 1977.

[7] Amin, M/B. and Benson, F.A., Coaxial cables as sources of intermodulation interference at microwave frequencies, IEEE Transactions on Electromagnetic Compatibility EMC-20(3); Aug. 1978.

[8] Arazm, F. and Benson, F.A., Nonlinearities in metal contacts at microwave frequencies, IEEE 
Transactions on Electromagnetic Compatibility EMC-22(3): 142-149; Aug. 1980.

[9] Kumar, A., Passive IM products threaten high-power satcom systems, Microwaves \& RF: 98103; Dec. 1987.

[10] Lui, P.L., Rawlins, A.D., and Watts, D.W., Measurement of intermodulation products generated by structural components, Electronics Letters 24(16): 1005-1007; Aug. 1988.

[11] Foord, A.P. and Rawlins, A.D., A study of passive intermodulation interference in space if hardware, ESTEC Contract 111036 Final Report, University of Kent at Canterbury; May 1992.

[12] Carlson, B., RF/microwave connector design for low intermodulation generation, Interconnection Technology: 23-27; Jul. 1993.

[13] Petit, J.S., Rawlins, A.D., and Mitchell, S.D., PIM characterisation of ESTEC CPTR for ARTEMIS PIM testing, JSP/ESCTEC/03/96 Final Report, University of Kent at Canterbury; Mar. 1996.

[14] Petit, J.S. and Rawlins, A.D., A study of multipaction in multicarrier rf components, Volume 2 WP2100: Anomalous Effects; Sep. 1996.

[15] Petit, J.S. and Rawlins, A.D., The impact of passive intermodulation on specifying and characterizing components, Proceedings Third ESA Electronic Components Conference: 45-49; Jul. 1997.

[16] Paynter, J.D. and Smith, R., Coaxial connectors: 7/16 DIN and type N, Mobile Radio Technology; Apr. 1995.

[17] International Electrotechnical Commission, RF connectors, connector cable assemblies and cables - intermodulation level measurement, Technical Committee 46, Working Group 6.

[18] Jargon, J.A., DeGroot, D.C., and Reed, K.L., NIST passive intermodulation measurement comparison for wireless base station equipment, 52nd ARFTG Conference Digest: 128-139, Rohnert Park, CA; Dec. 1998.

[19] Rosenberger, B., The measurement of intermodulation products on passive components and transmission lines, 50th ARFTG Conference Digest: 13-22, Portland, OR; Dec. 1997.

[20] Deats, B. and Hartman, R., Measuring the passive-IM performance of rf cable assemblies, Microwaves \& RF: 108-114; Mar. 1997. 


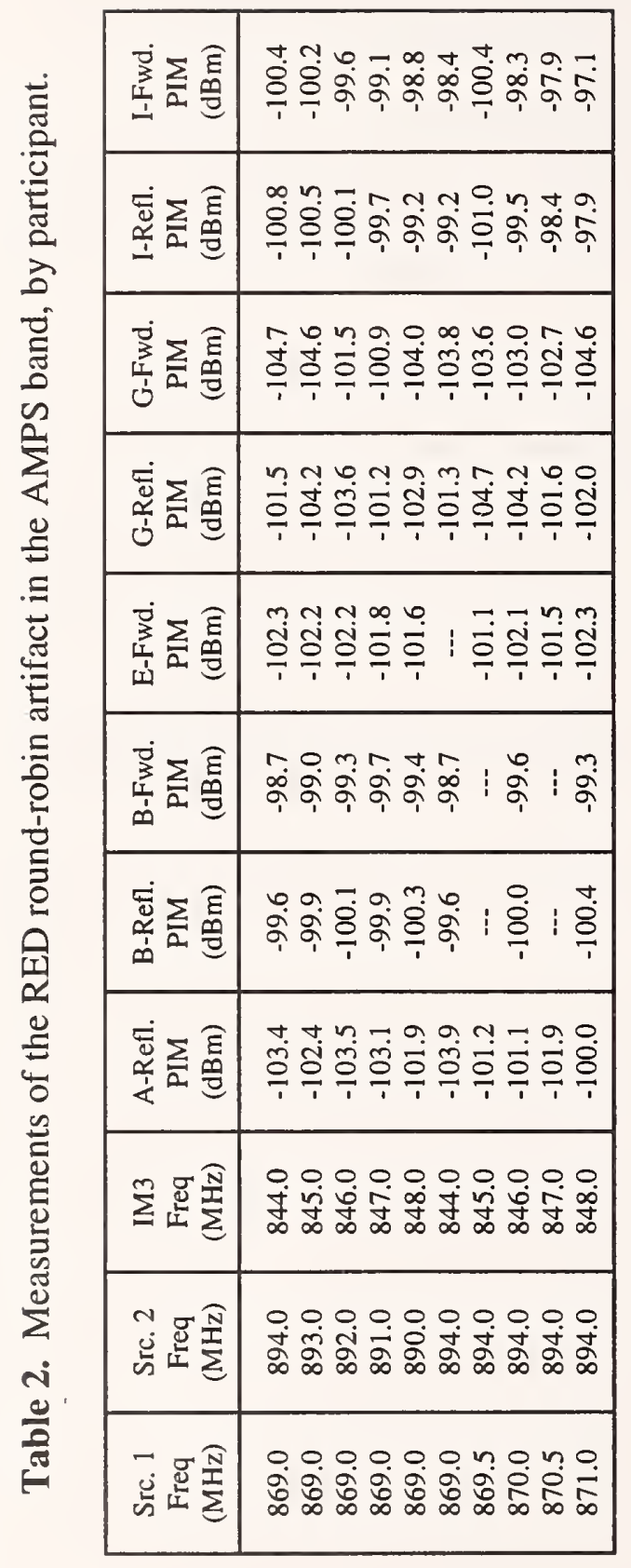

\begin{tabular}{|c|c|}
\hline 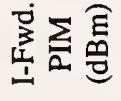 & 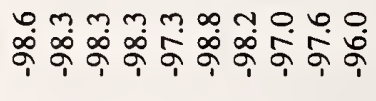 \\
\hline 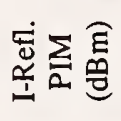 & 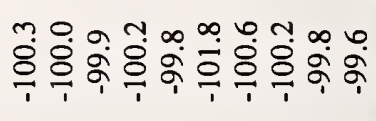 \\
\hline 旁主曼 & 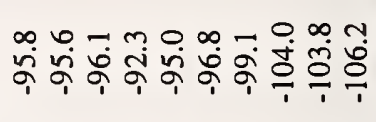 \\
\hline 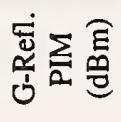 & 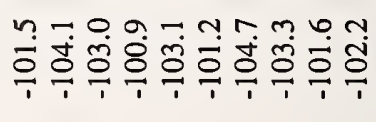 \\
\hline 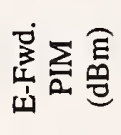 & 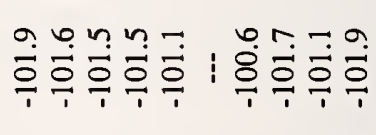 \\
\hline 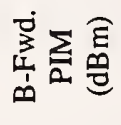 & 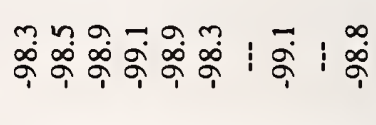 \\
\hline 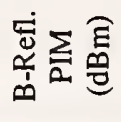 & 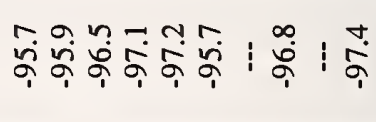 \\
\hline 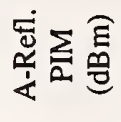 & 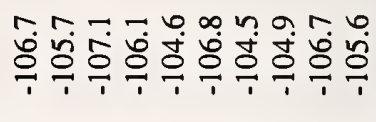 \\
\hline 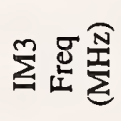 & 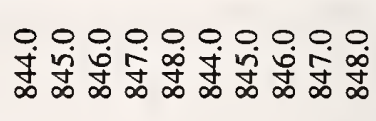 \\
\hline 总蛋 & 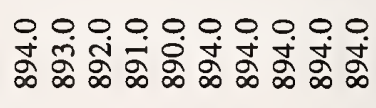 \\
\hline 总昰全 & 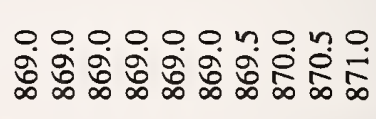 \\
\hline
\end{tabular}




\begin{tabular}{|c|c|}
\hline 空刻总 & 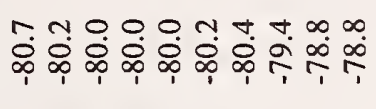 \\
\hline 悹总产 & 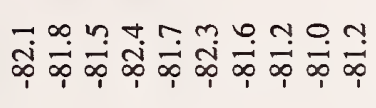 \\
\hline 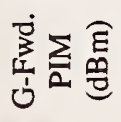 & 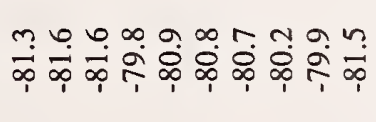 \\
\hline 密空产 & 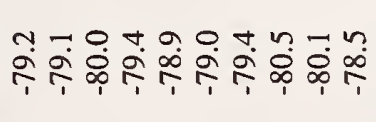 \\
\hline 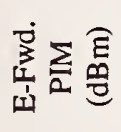 & 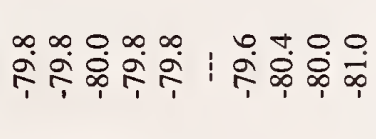 \\
\hline 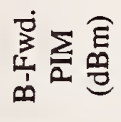 & 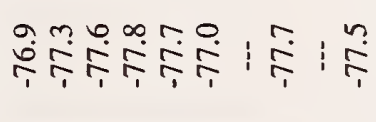 \\
\hline 离骇是 & 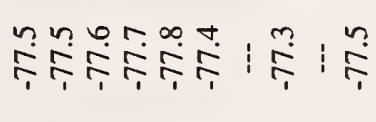 \\
\hline 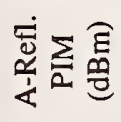 & 幽 \\
\hline 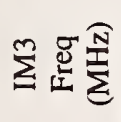 & 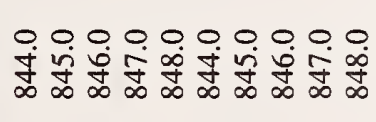 \\
\hline 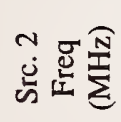 & 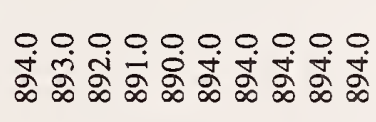 \\
\hline 它总全 & 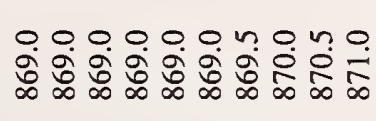 \\
\hline
\end{tabular}

\begin{tabular}{|c|c|}
\hline 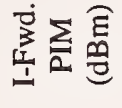 & 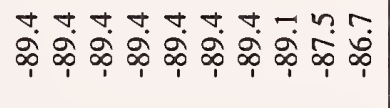 \\
\hline $\begin{array}{l}\text { 这 } \\
\text { 产产 }\end{array}$ & 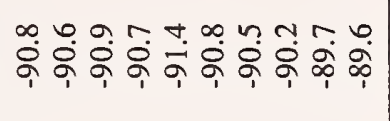 \\
\hline 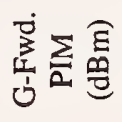 & 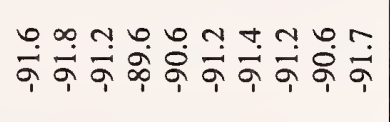 \\
\hline 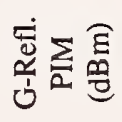 & 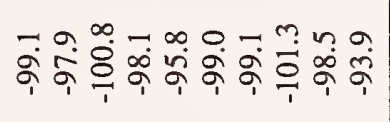 \\
\hline 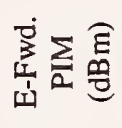 & 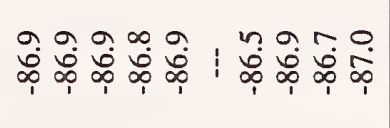 \\
\hline 蛋主魚 & 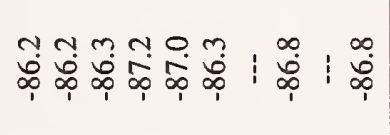 \\
\hline 密既 & 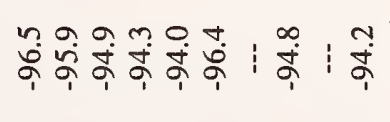 \\
\hline 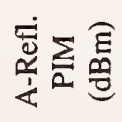 & 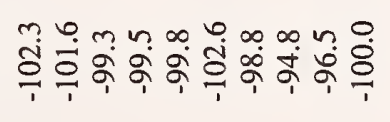 \\
\hline 蛋蛋 & 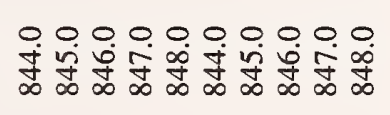 \\
\hline 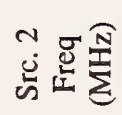 & 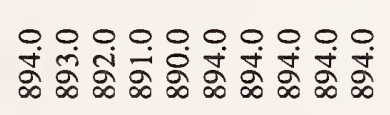 \\
\hline 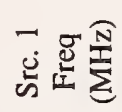 & 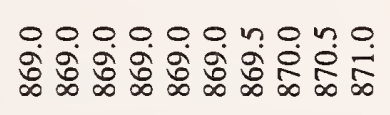 \\
\hline
\end{tabular}



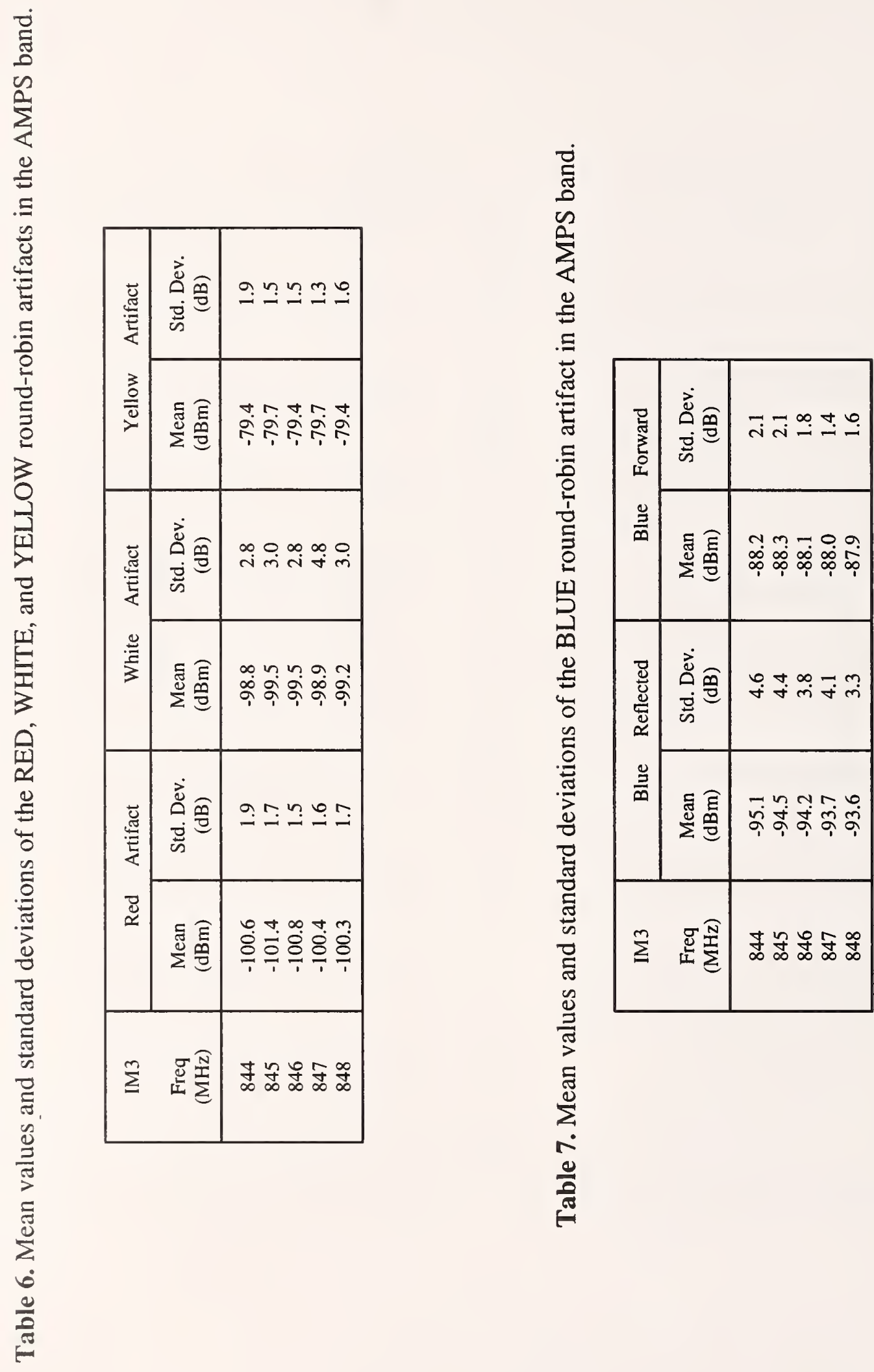


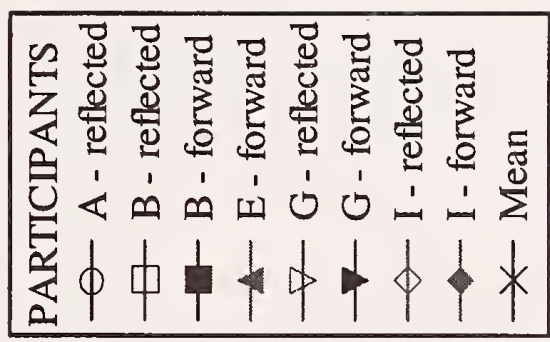

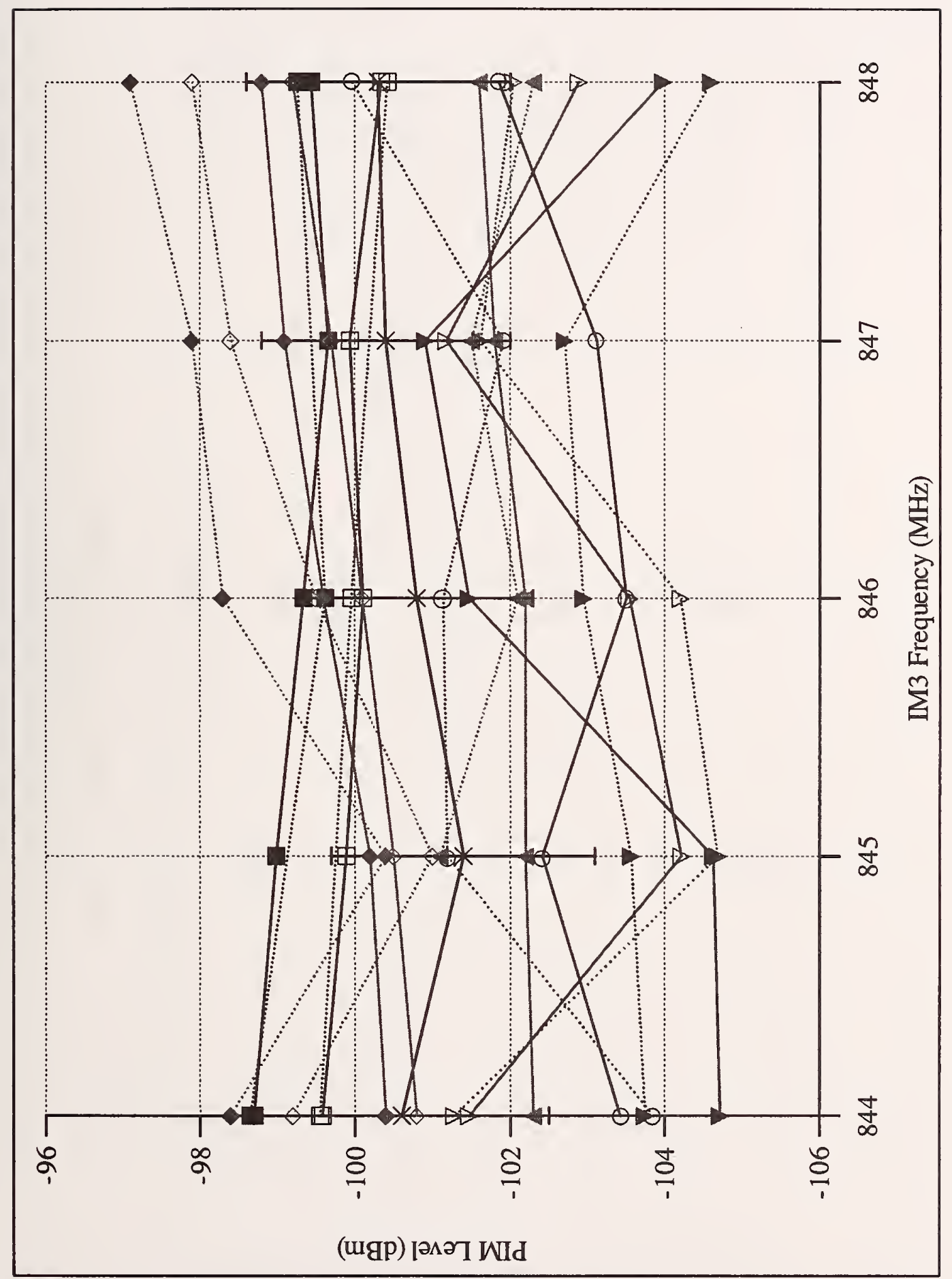

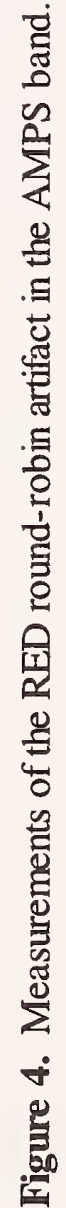



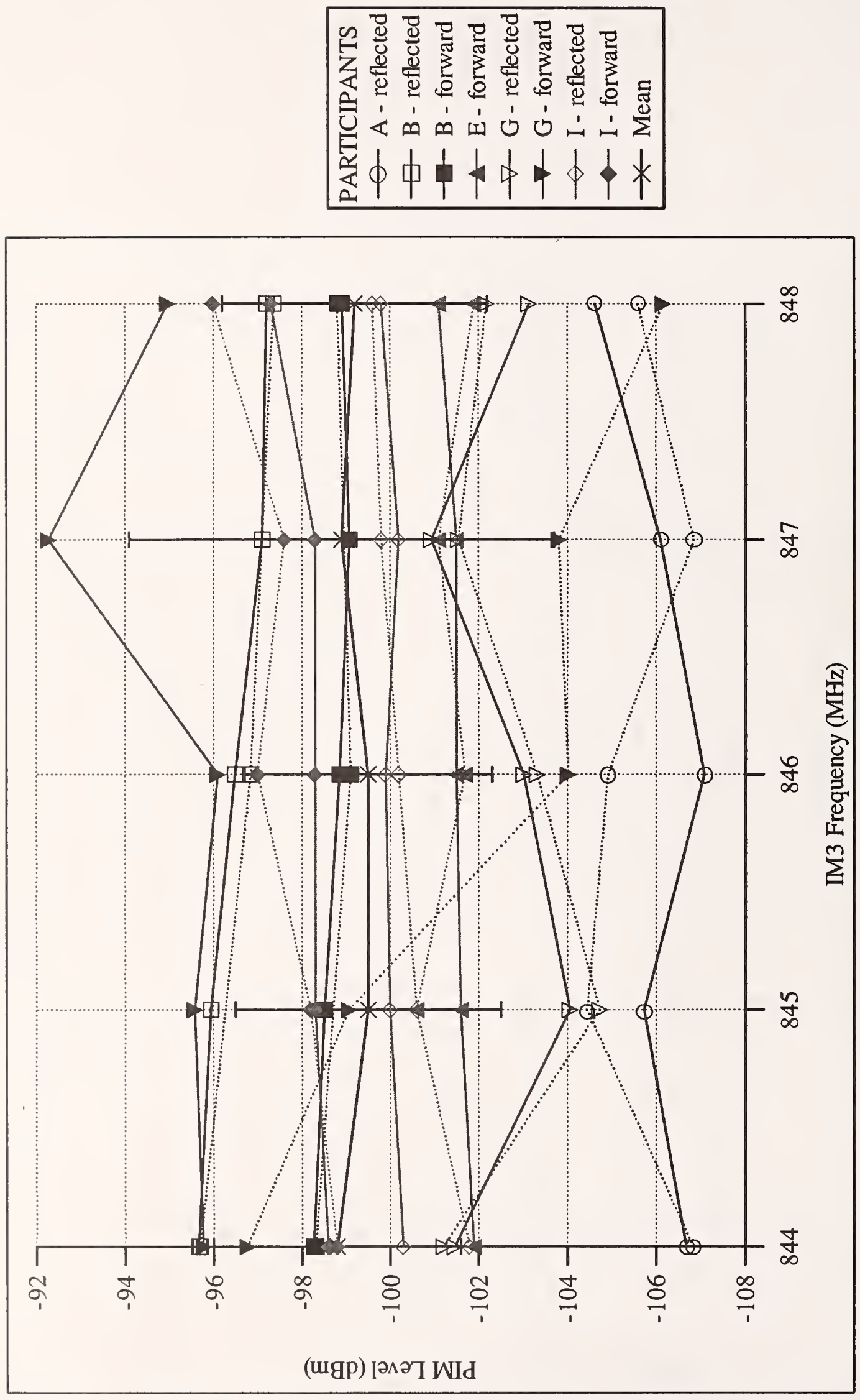

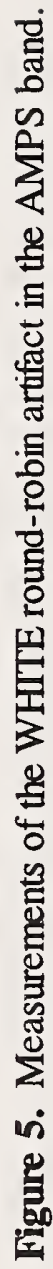



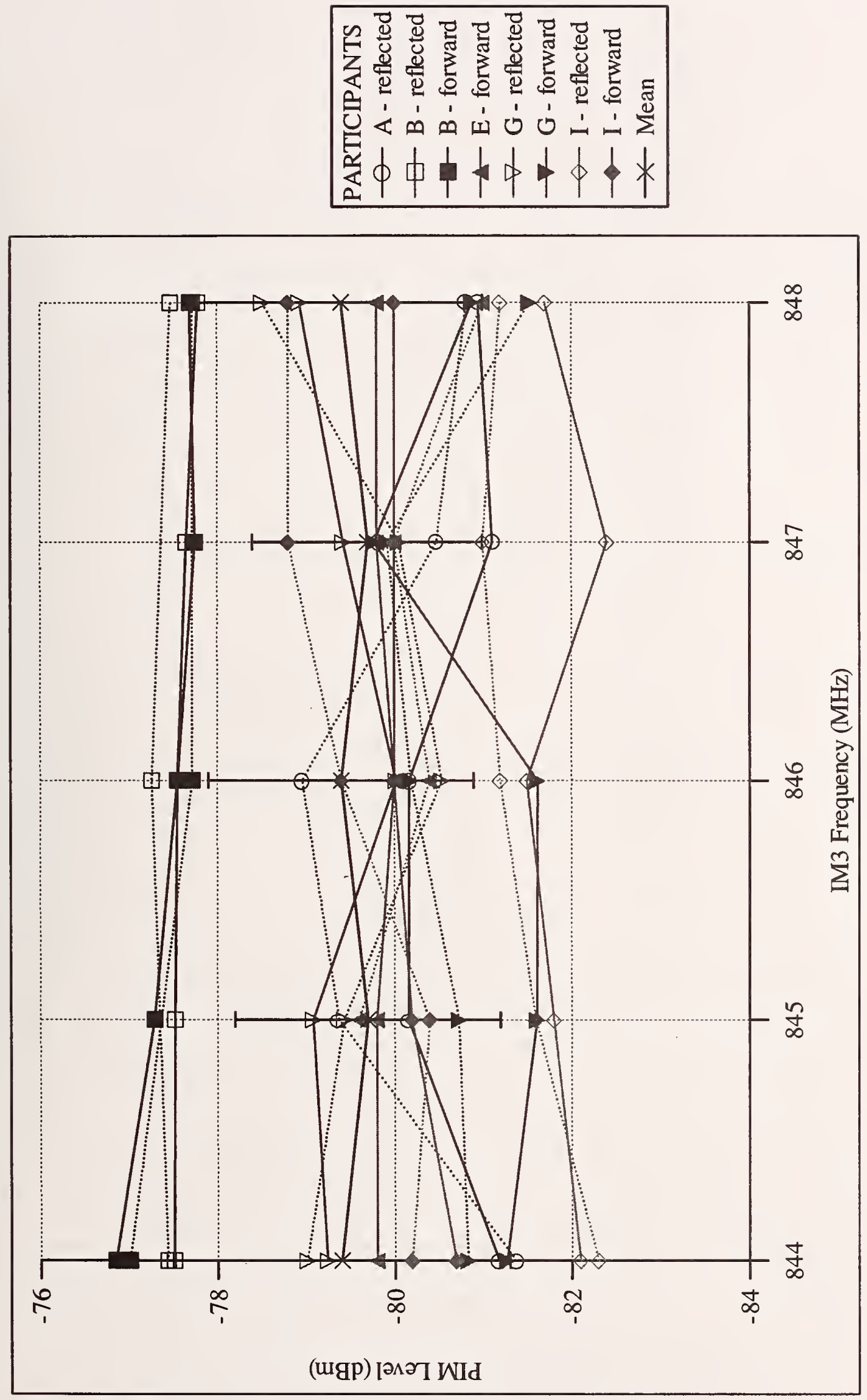

吾 

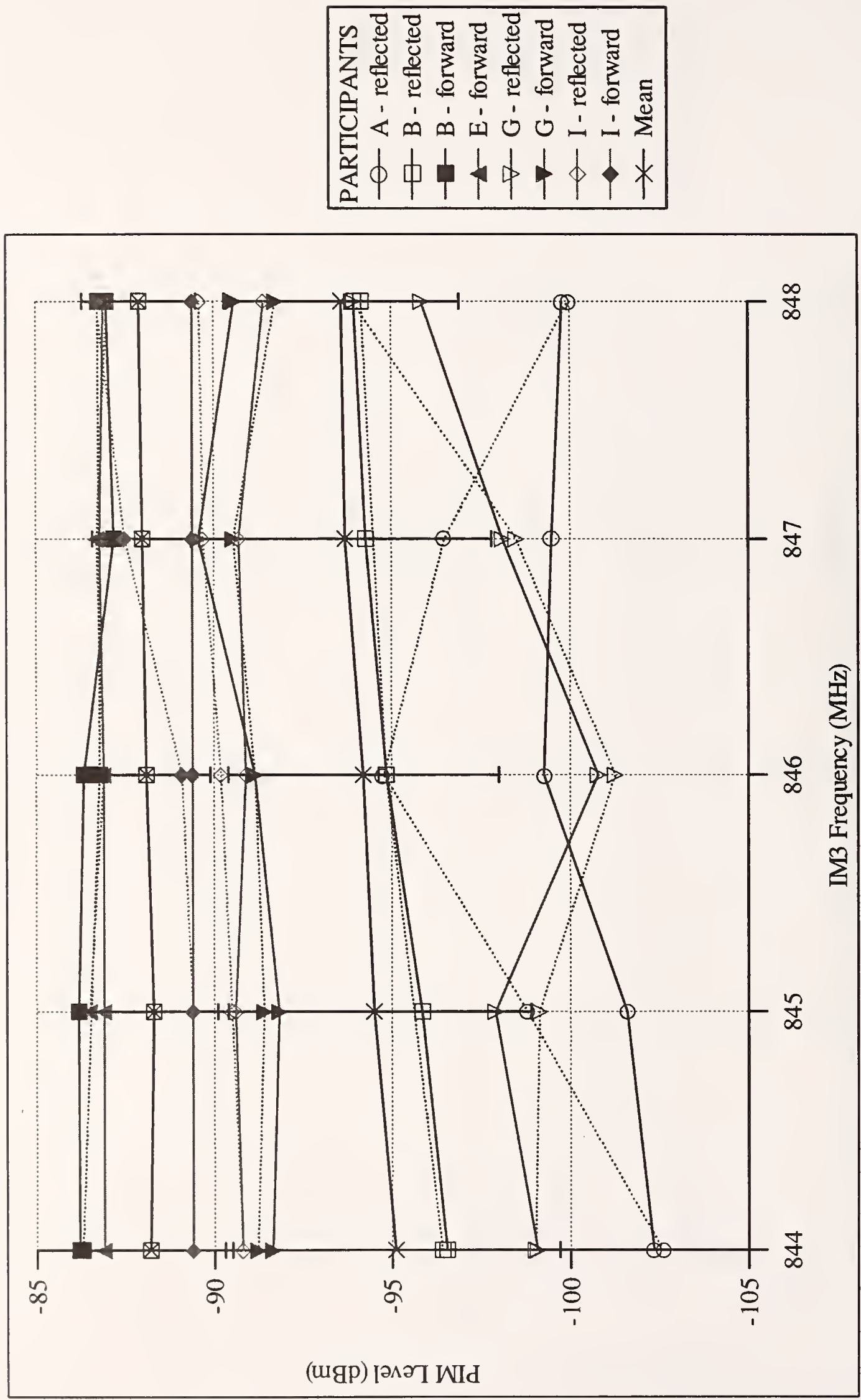

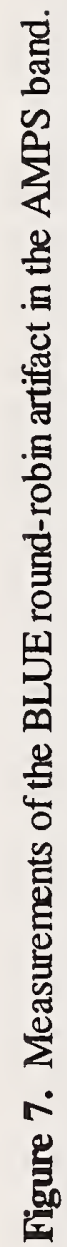




\begin{tabular}{|c|c|}
\hline 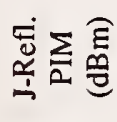 & 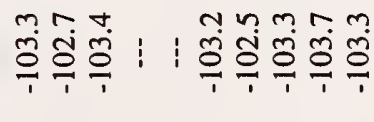 \\
\hline 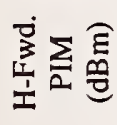 & $1: 1: 1: 10: 10 \%$ \\
\hline 离交高 & 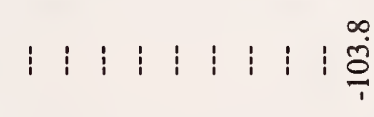 \\
\hline 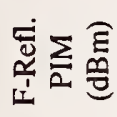 & 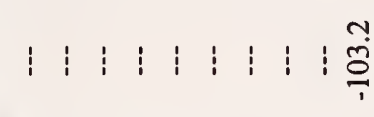 \\
\hline 产部善 & 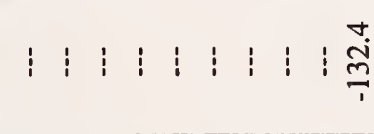 \\
\hline 离衣言 & 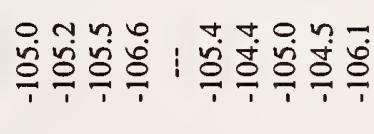 \\
\hline 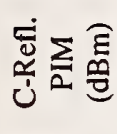 & 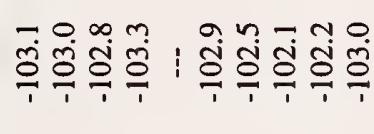 \\
\hline 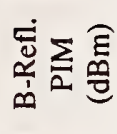 & $1: 1: 1: 1: 1: 1: 1:=\frac{\bar{\Xi}}{1}$ \\
\hline 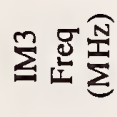 & 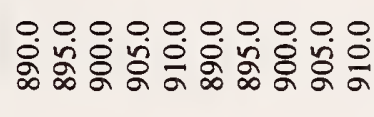 \\
\hline 론 & 宫 \\
\hline 它点全 & 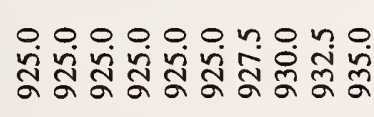 \\
\hline
\end{tabular}

\begin{tabular}{|c|c|}
\hline 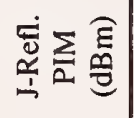 & 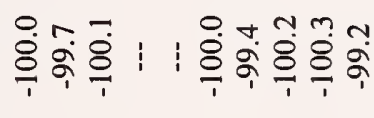 \\
\hline 密主魚 & $1 \quad 1 \quad 1 \quad 1 \quad 1 \quad 1 \quad 1 \quad 1 \quad 1$ \\
\hline 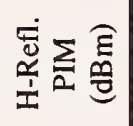 & 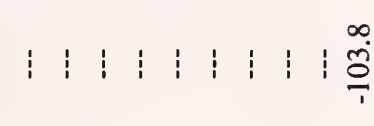 \\
\hline 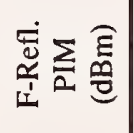 & $1: 1: 10: 1: 1011$ \\
\hline 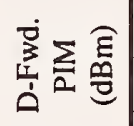 & $1: 1: 11: 11$ \\
\hline 离空既 & 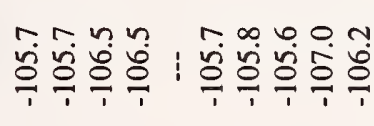 \\
\hline 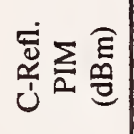 & 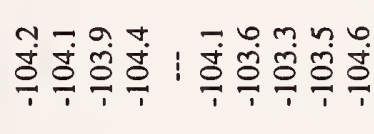 \\
\hline 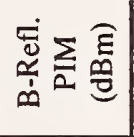 & 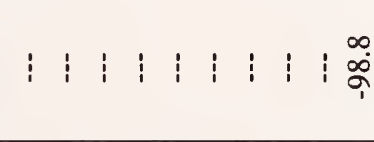 \\
\hline 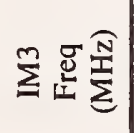 & 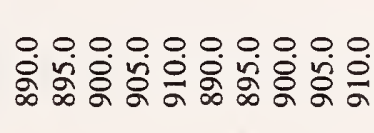 \\
\hline N & 연. \\
\hline 恙焉全 & 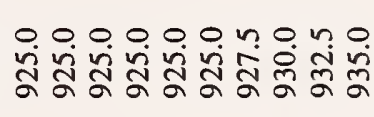 \\
\hline
\end{tabular}




\begin{tabular}{|c|c|}
\hline 密密高 & 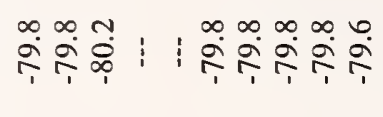 \\
\hline 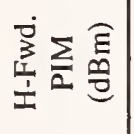 & 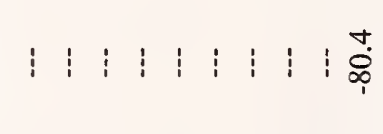 \\
\hline 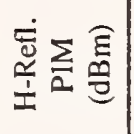 & $1: 1: 5: 11: 1: 1$ \\
\hline 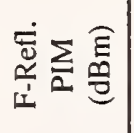 & 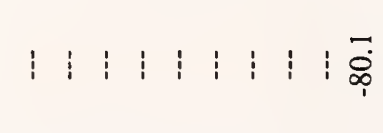 \\
\hline 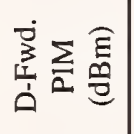 & 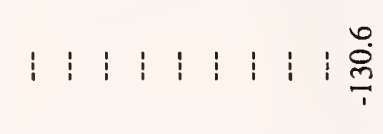 \\
\hline 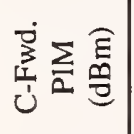 & 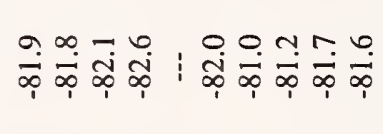 \\
\hline 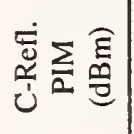 & 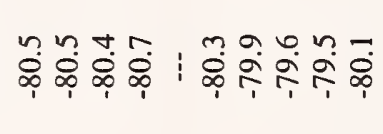 \\
\hline 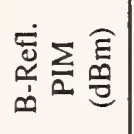 & 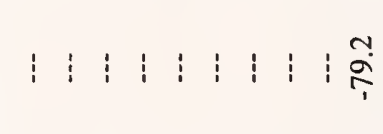 \\
\hline 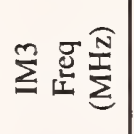 & 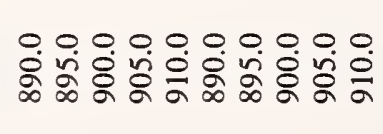 \\
\hline 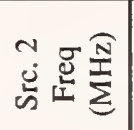 & 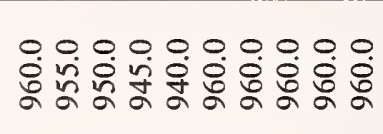 \\
\hline 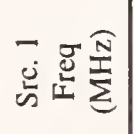 & 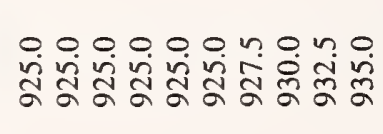 \\
\hline
\end{tabular}

\begin{tabular}{|c|c|}
\hline 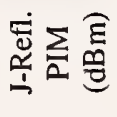 & 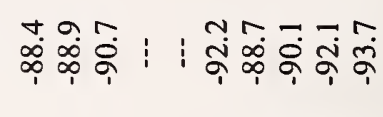 \\
\hline 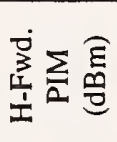 & 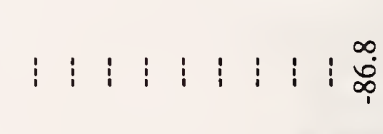 \\
\hline 突突高 & $1: 1: 1: 1: 1: 1: \stackrel{\infty}{0}$ \\
\hline 灾 & ：：：：：：：：：：亲 \\
\hline 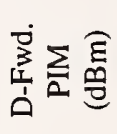 & 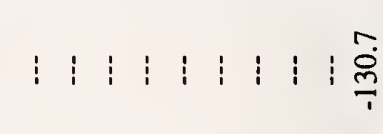 \\
\hline 竞衣镸 & 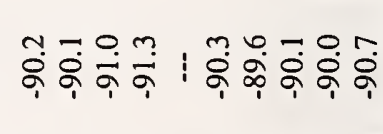 \\
\hline 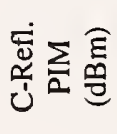 & 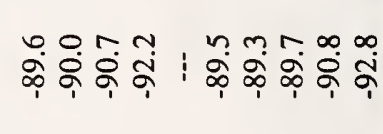 \\
\hline 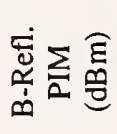 & 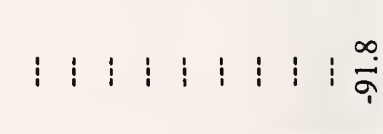 \\
\hline 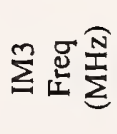 & 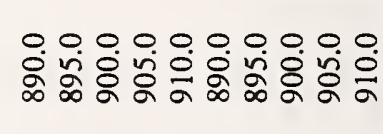 \\
\hline 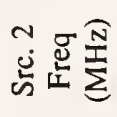 & 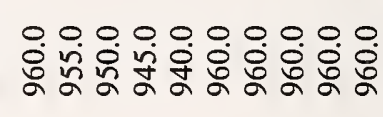 \\
\hline 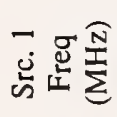 & 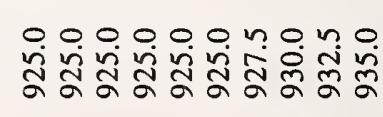 \\
\hline
\end{tabular}



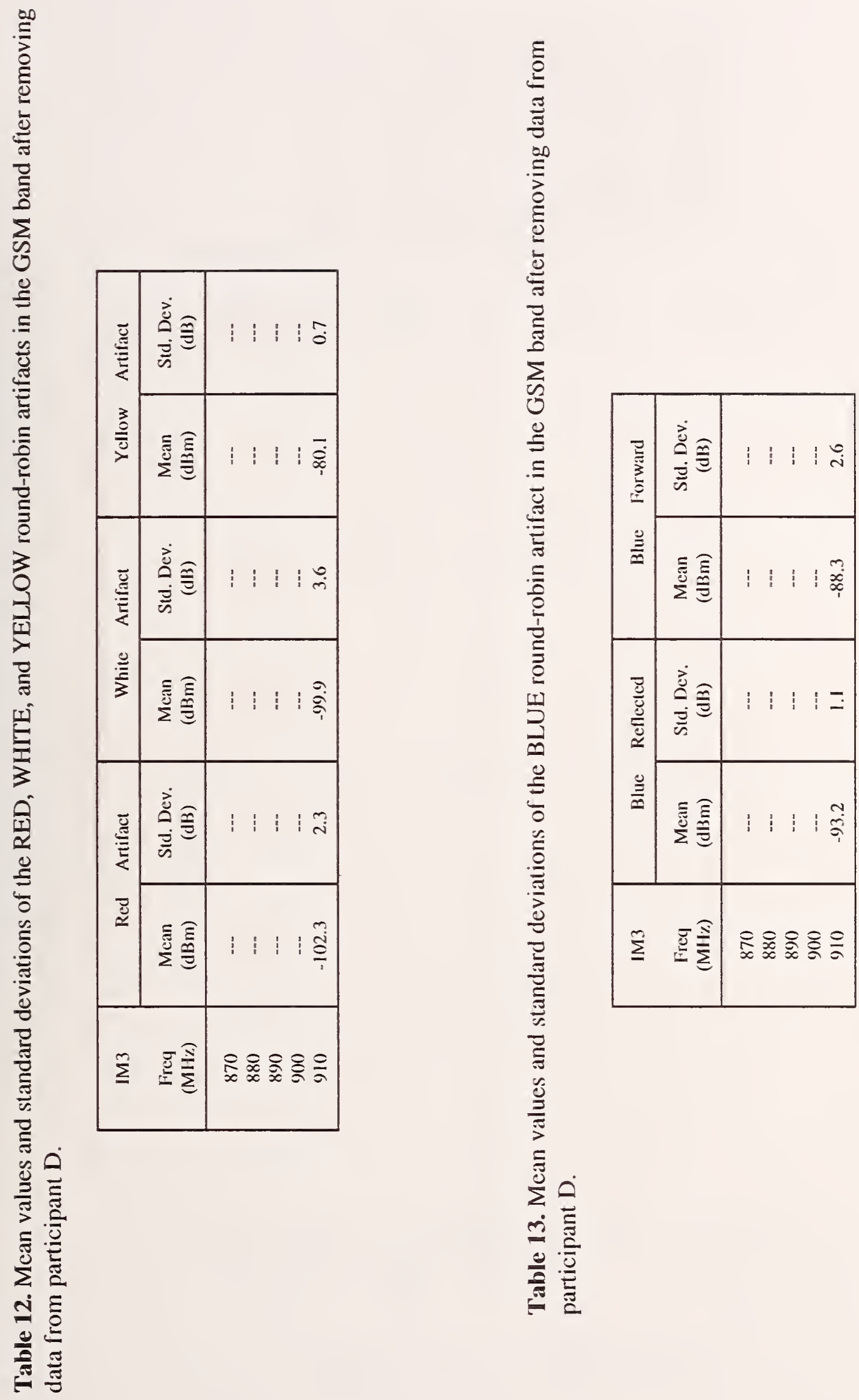

导

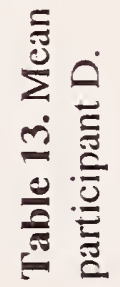



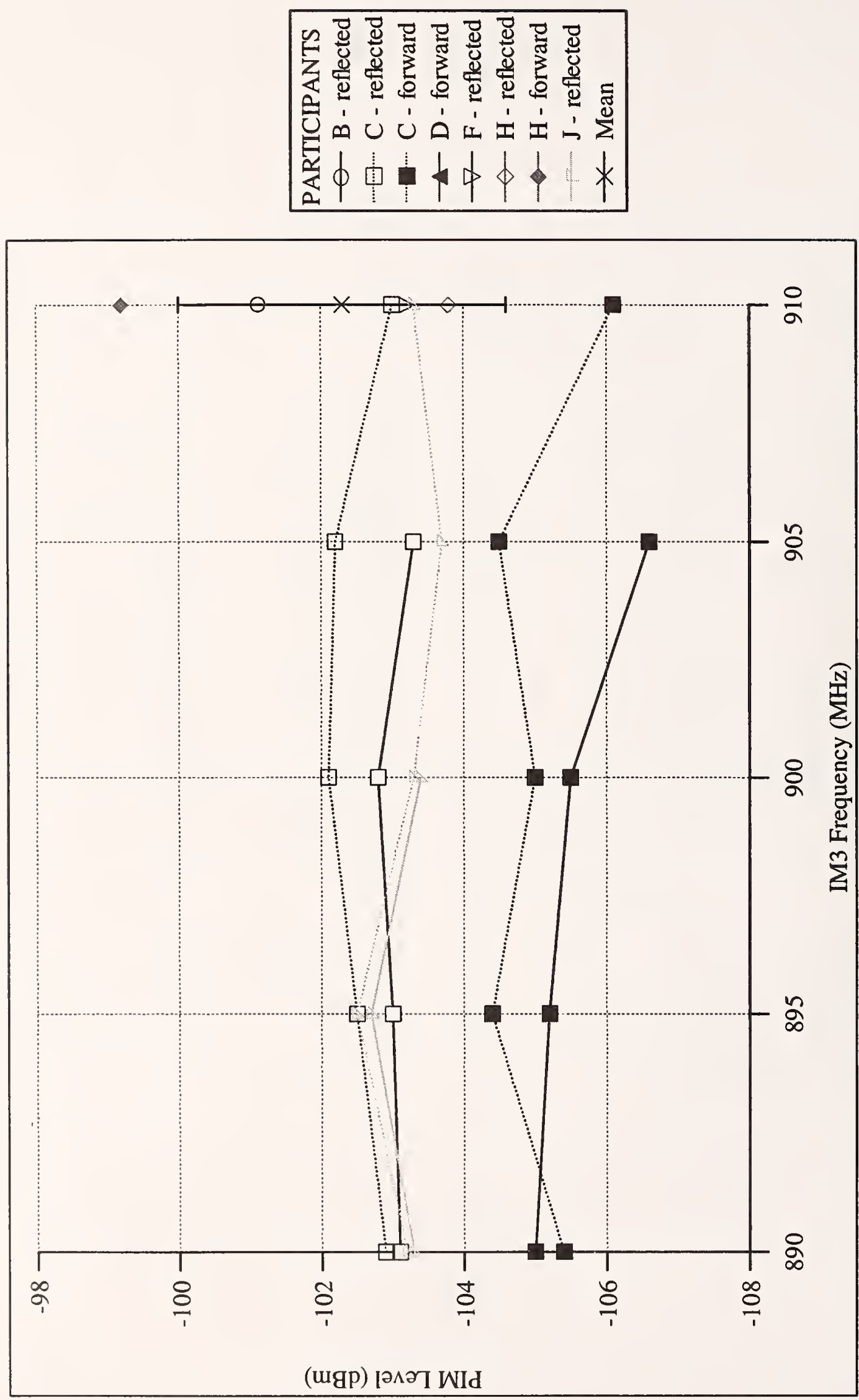

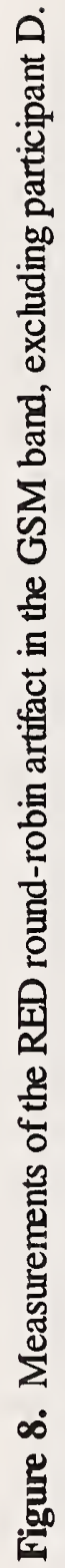




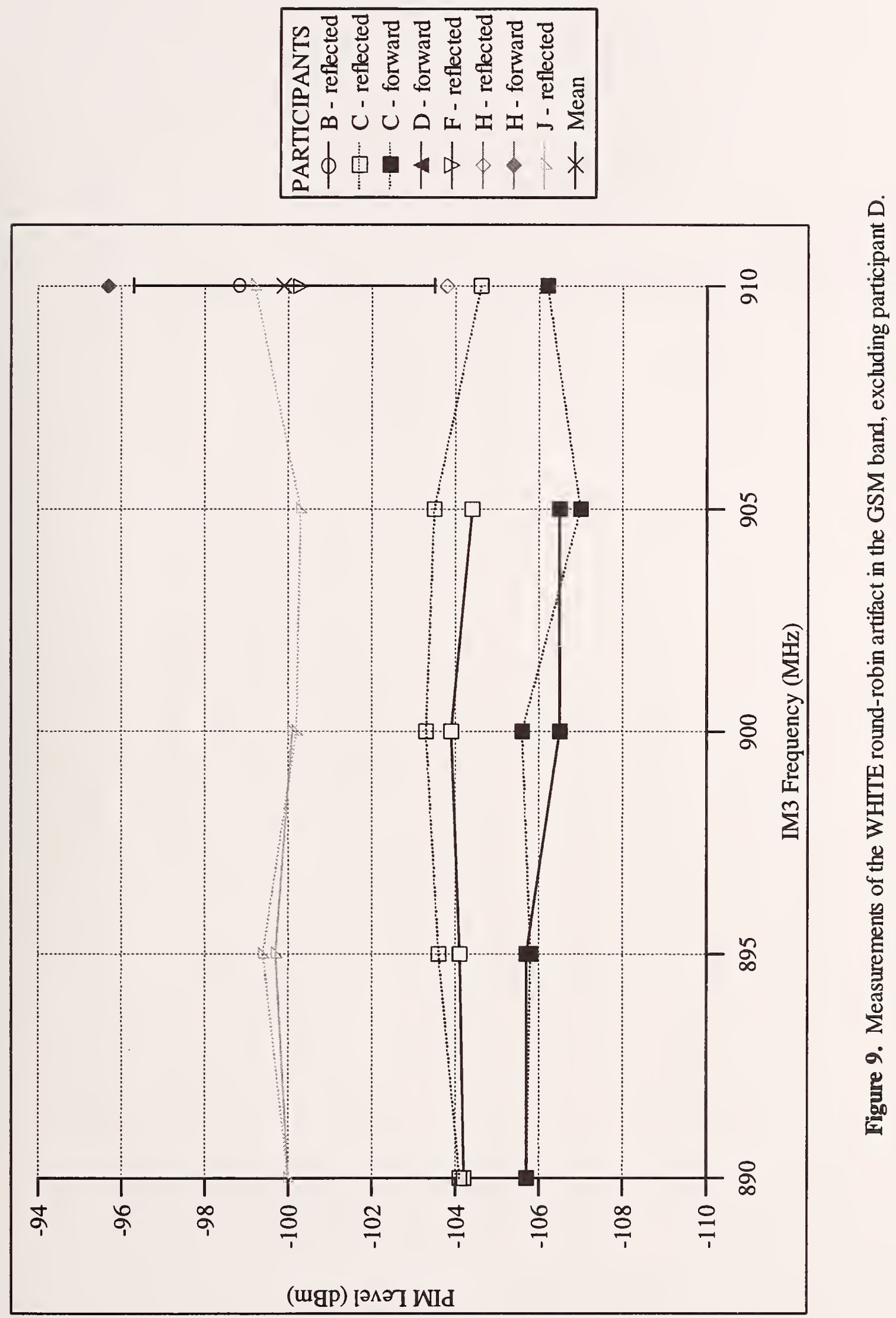




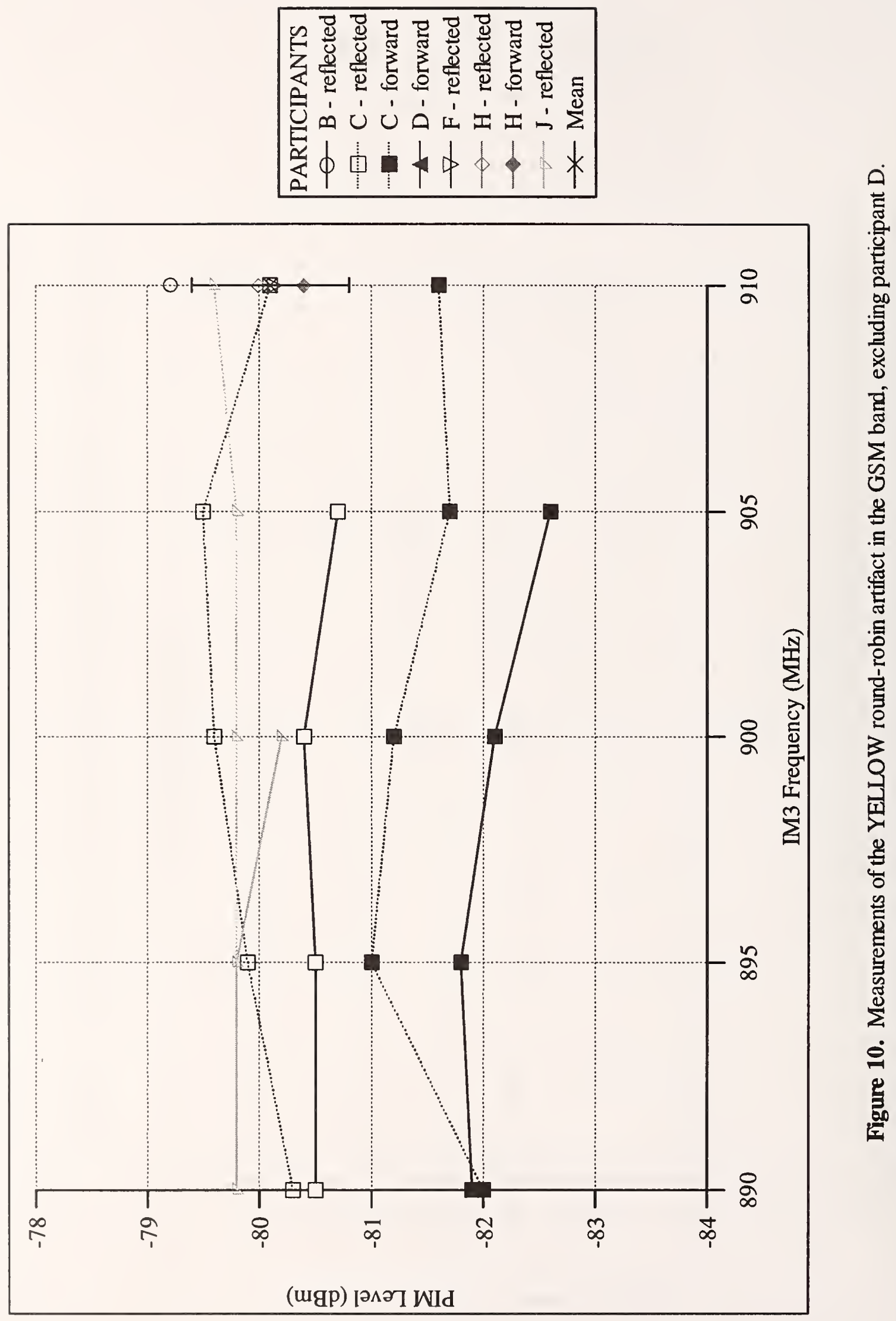




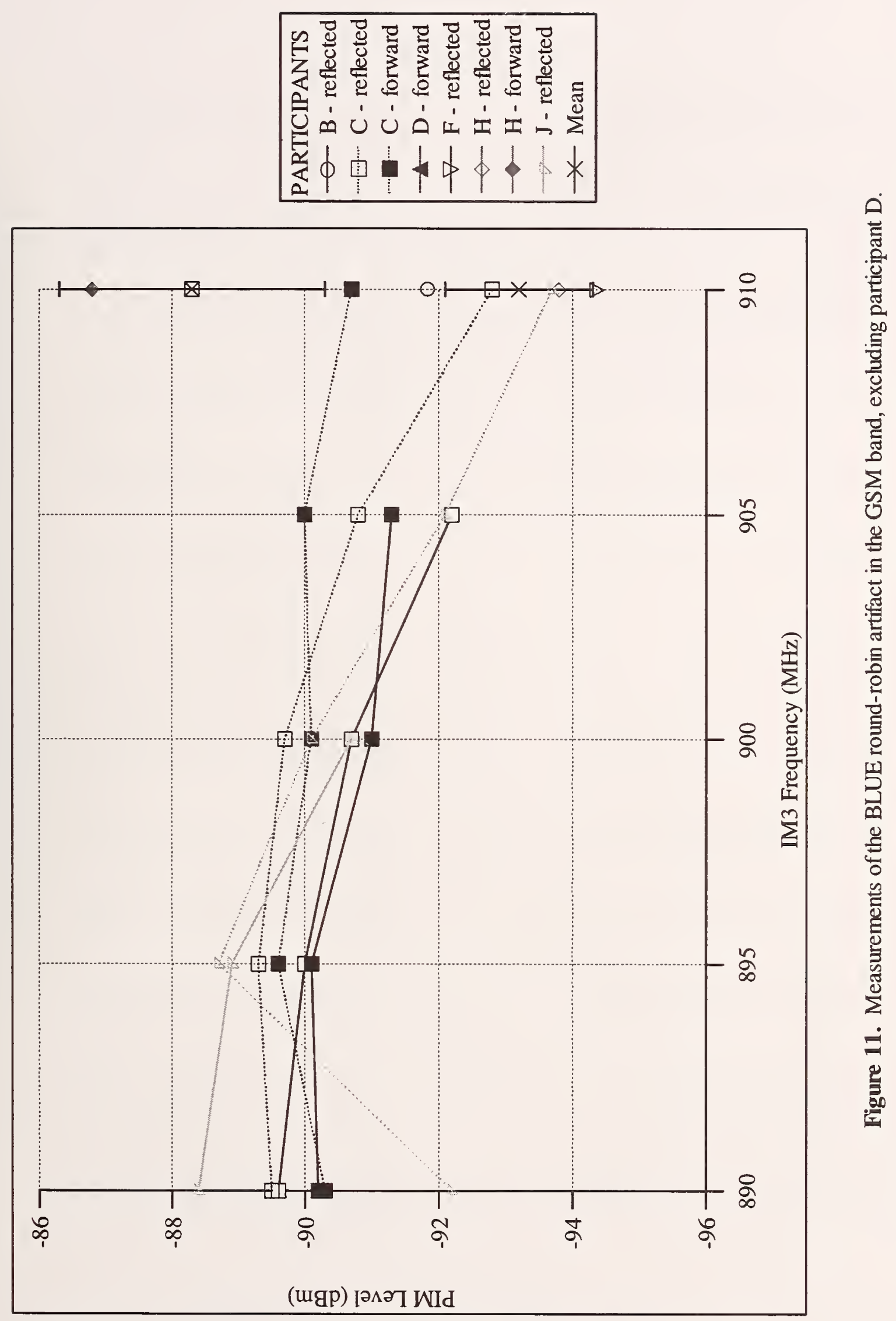




\begin{tabular}{|c|c|}
\hline 变既 & 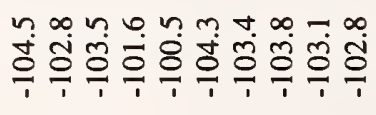 \\
\hline 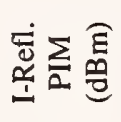 & 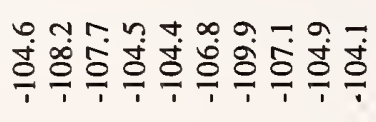 \\
\hline 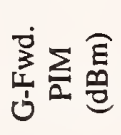 & 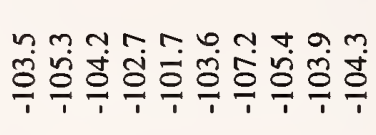 \\
\hline 窎 & 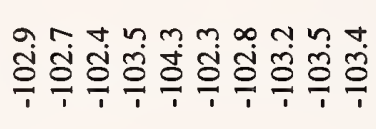 \\
\hline 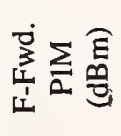 & 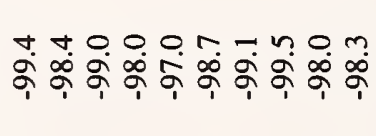 \\
\hline 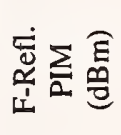 & 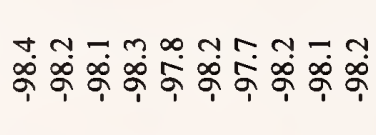 \\
\hline 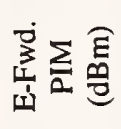 & 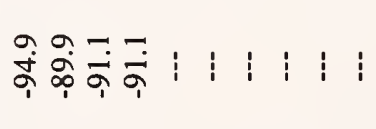 \\
\hline 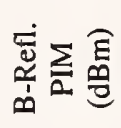 & 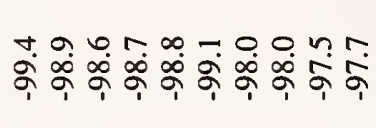 \\
\hline 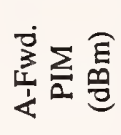 & 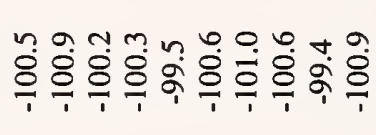 \\
\hline 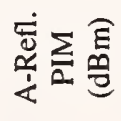 & 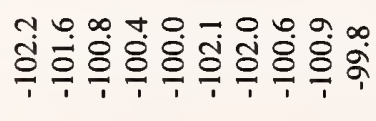 \\
\hline 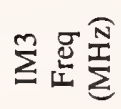 & 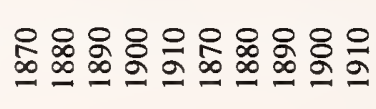 \\
\hline 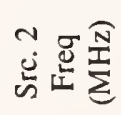 & 용ㅇㅇㅇㅇㅇㅇㅇㅇㅇㅇㅇㅇㅇㅇㅇㅇㅕ \\
\hline 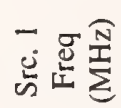 & 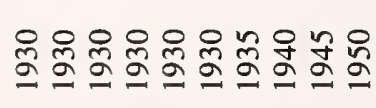 \\
\hline
\end{tabular}

\begin{tabular}{|c|c|}
\hline 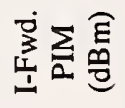 & 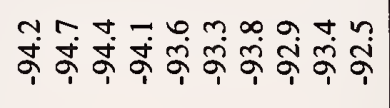 \\
\hline 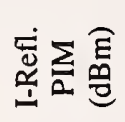 & 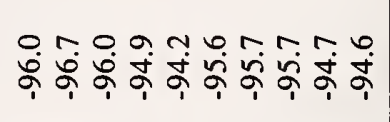 \\
\hline 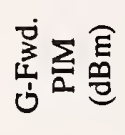 & 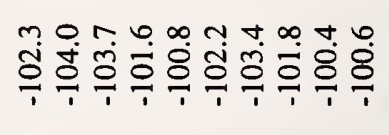 \\
\hline 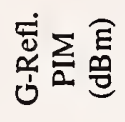 & 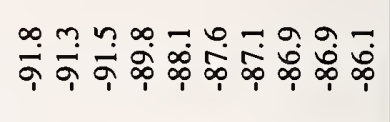 \\
\hline 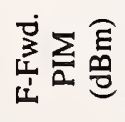 & 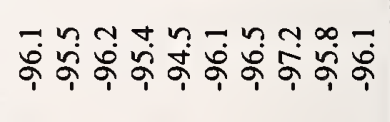 \\
\hline 离亥 & 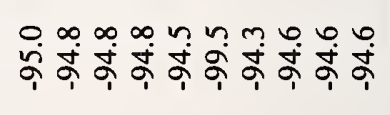 \\
\hline 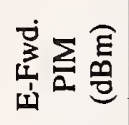 & 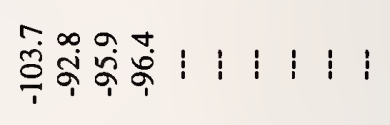 \\
\hline 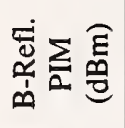 & 它 \\
\hline 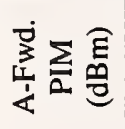 & 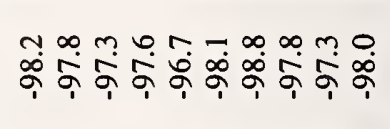 \\
\hline 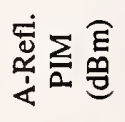 & 움 \\
\hline 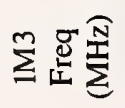 & $\begin{array}{l}\text { 용ㅇㅇㅇㅇㅇㅇㅇㅇㅇㅇㅇㅇㅇㅡ. } \\
\infty \cong \infty\end{array}$ \\
\hline 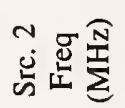 & 양ㅇㅇㅇㅇㅇㅇㅇㅇㅇㅇㅇㅇㅇㅇㅇㅇㅇㅇㅇ \\
\hline 它㥕吝 & 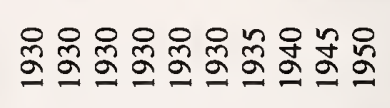 \\
\hline
\end{tabular}




\begin{tabular}{|c|c|}
\hline 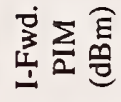 & 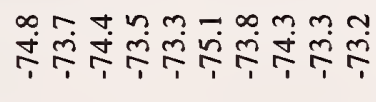 \\
\hline 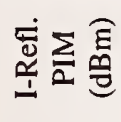 & 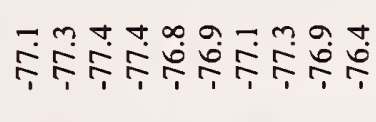 \\
\hline 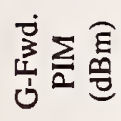 & 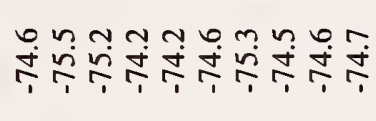 \\
\hline 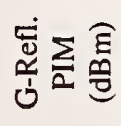 & 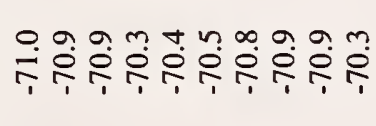 \\
\hline 畜亩 & 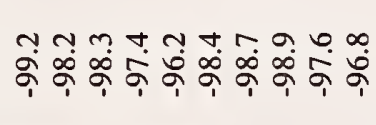 \\
\hline 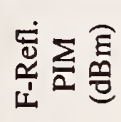 & 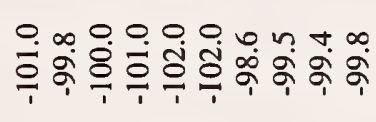 \\
\hline 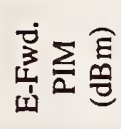 & 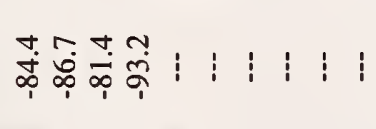 \\
\hline 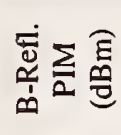 & 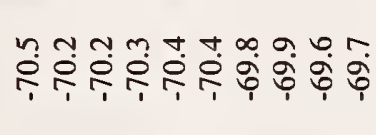 \\
\hline 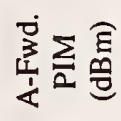 & m \\
\hline 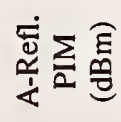 & 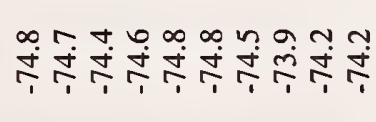 \\
\hline 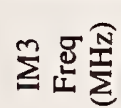 & 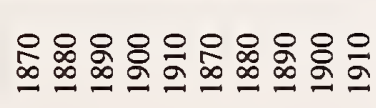 \\
\hline 离蛋蕞 & 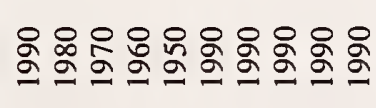 \\
\hline 它胥胥 & 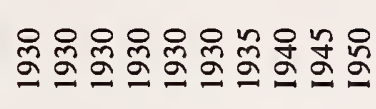 \\
\hline
\end{tabular}

\begin{tabular}{|c|c|}
\hline 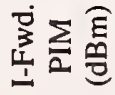 & 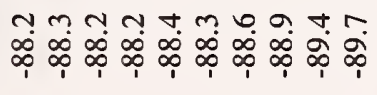 \\
\hline 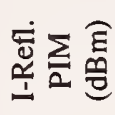 & 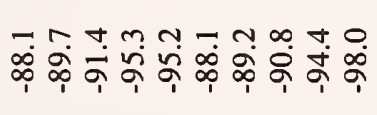 \\
\hline 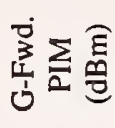 & 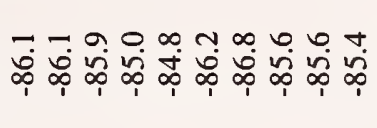 \\
\hline 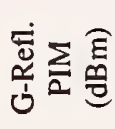 & 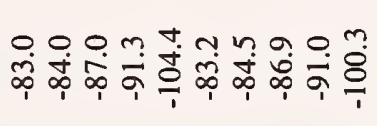 \\
\hline 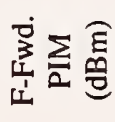 & 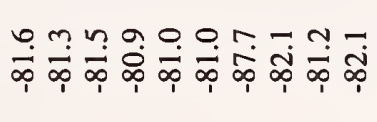 \\
\hline 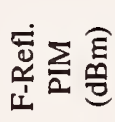 & 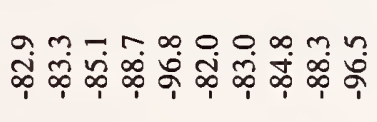 \\
\hline 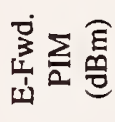 & 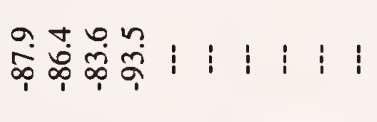 \\
\hline 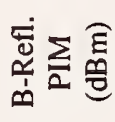 & 芯 舟 \\
\hline 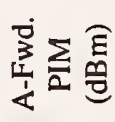 & 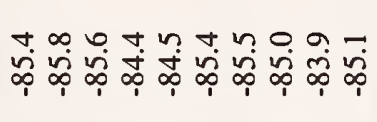 \\
\hline 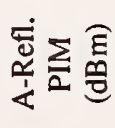 & 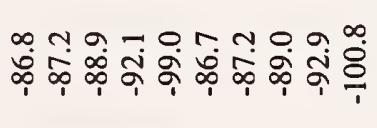 \\
\hline$\sum_{\Sigma}^{m}$ 蛋疍 & 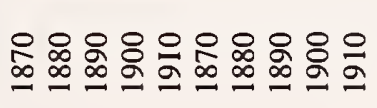 \\
\hline 总疍 & 응옹양응영영영영 \\
\hline 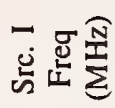 & 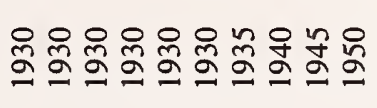 \\
\hline
\end{tabular}



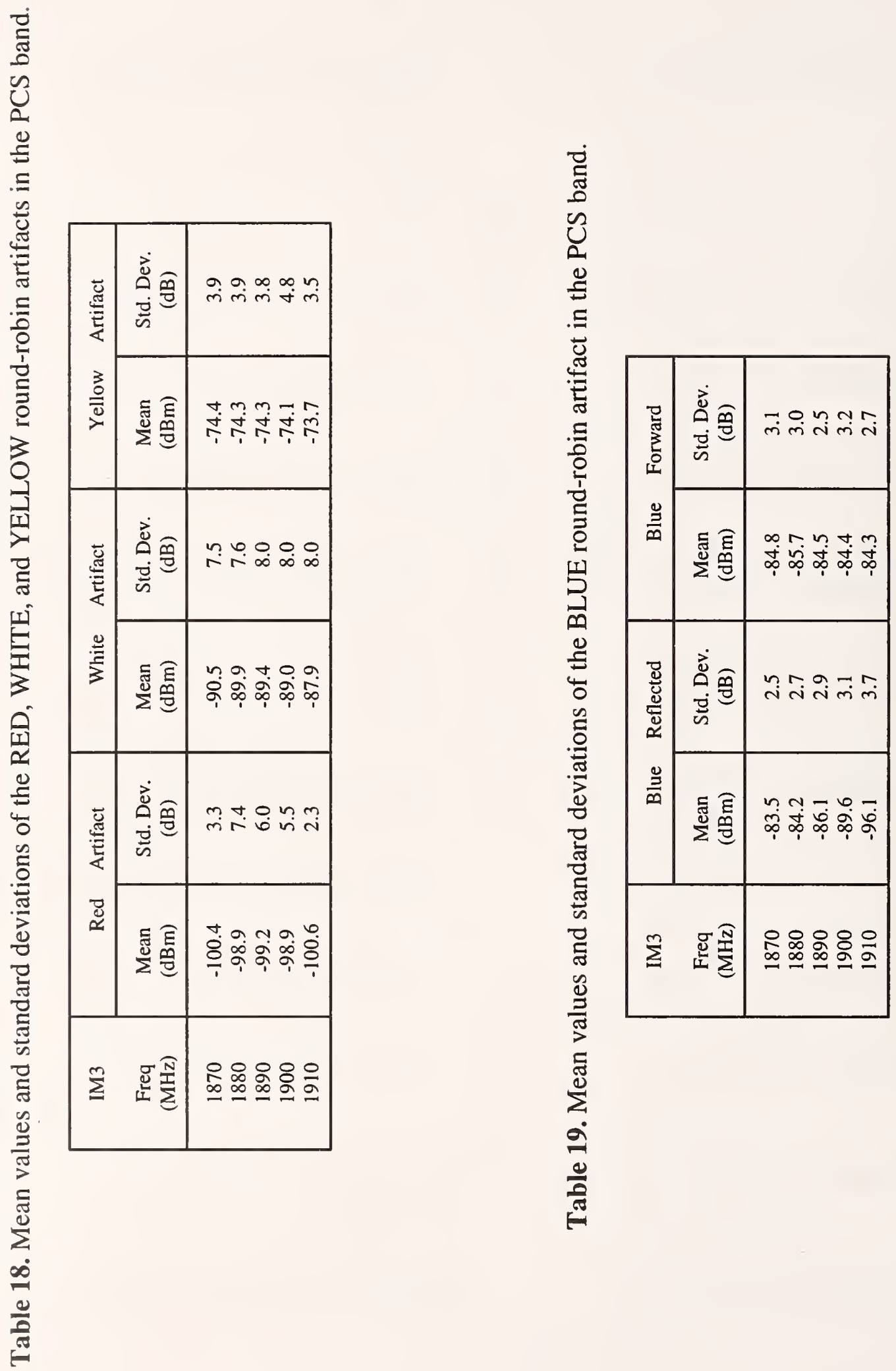

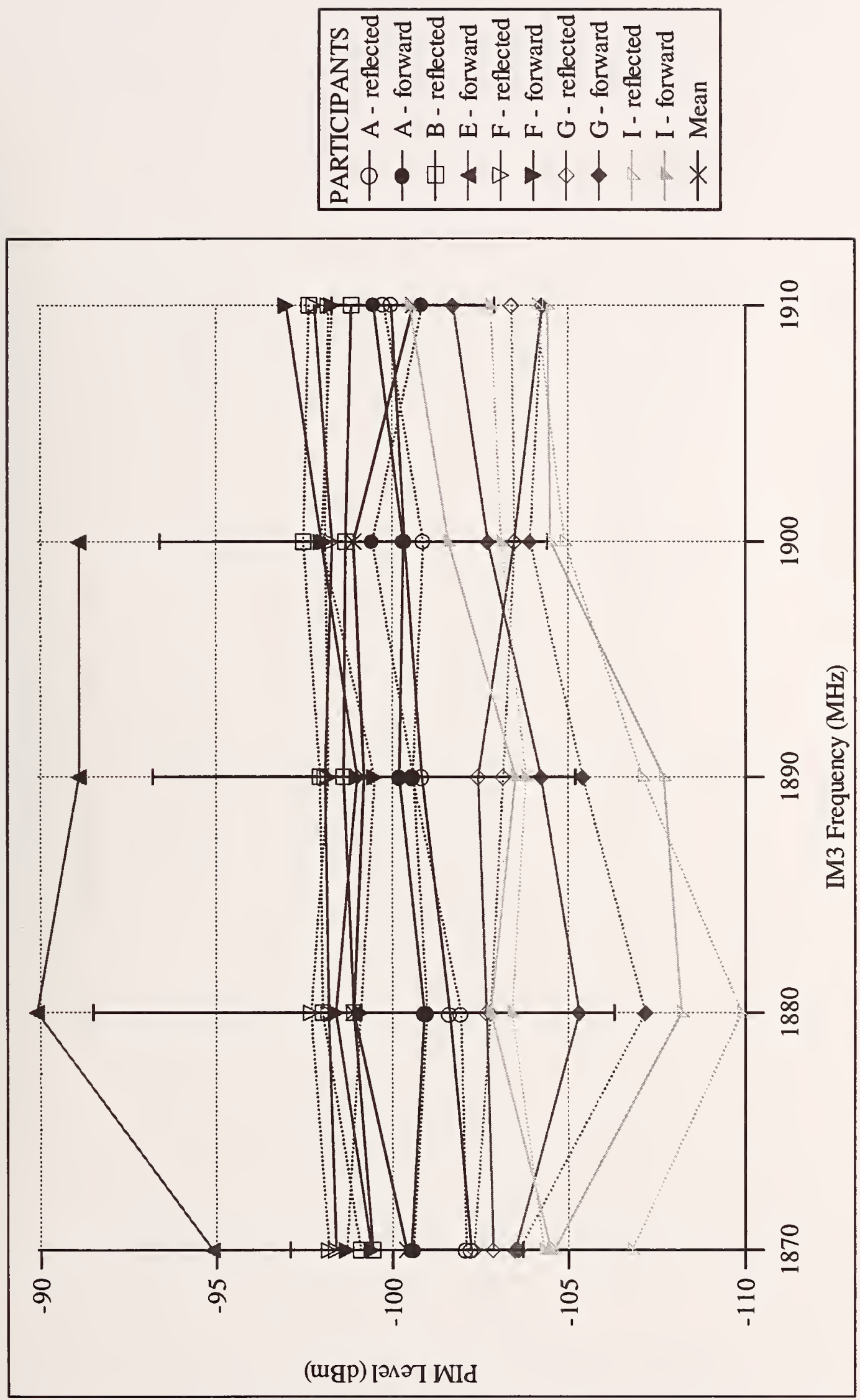

告 

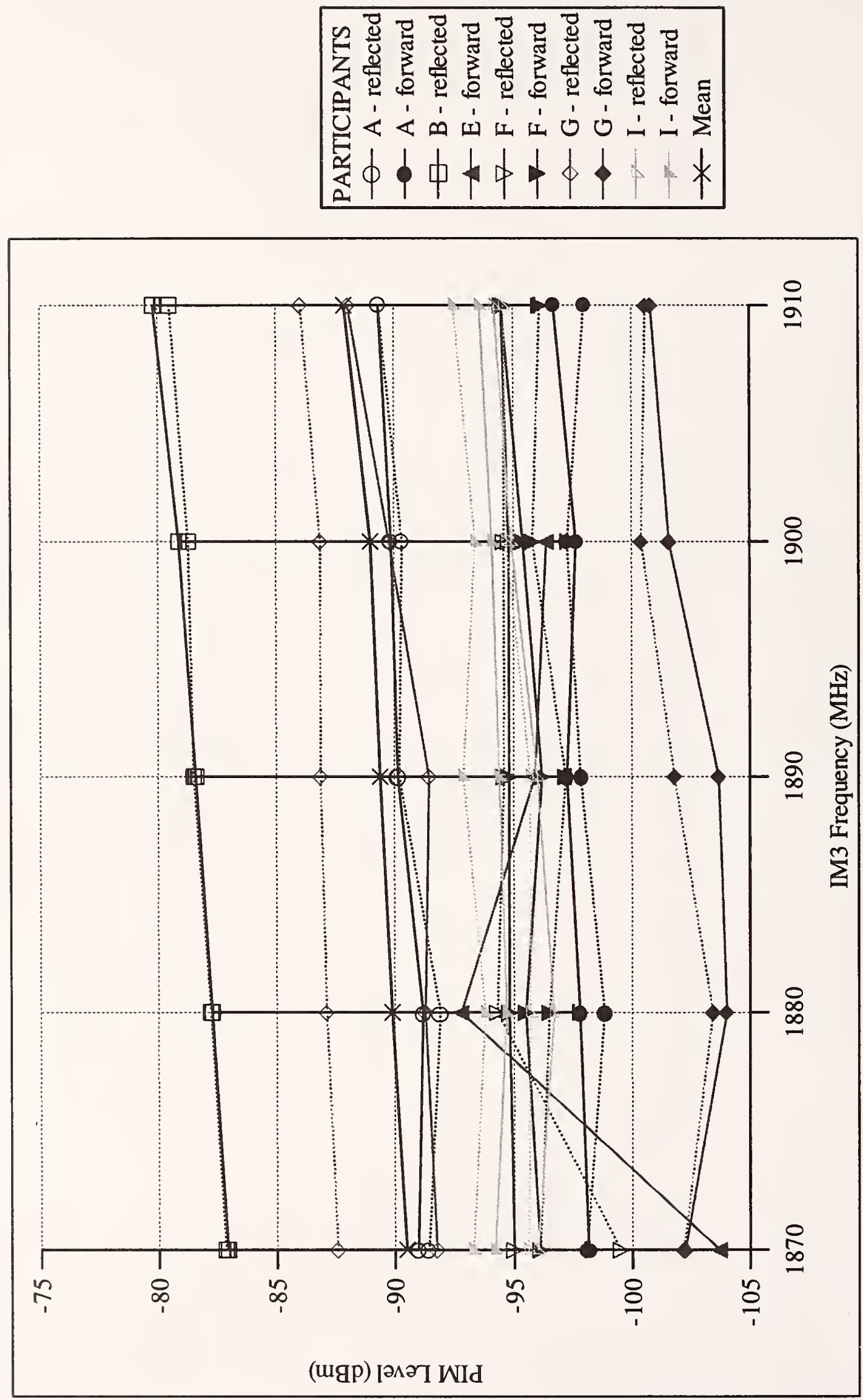

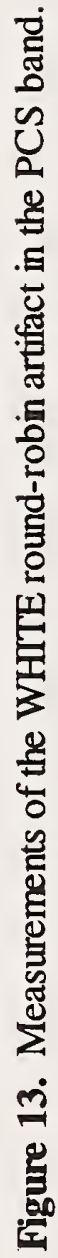




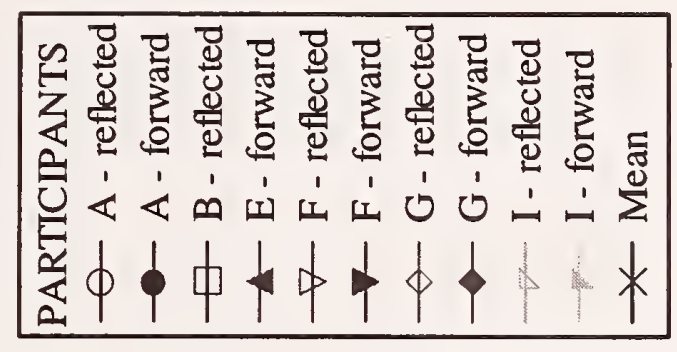

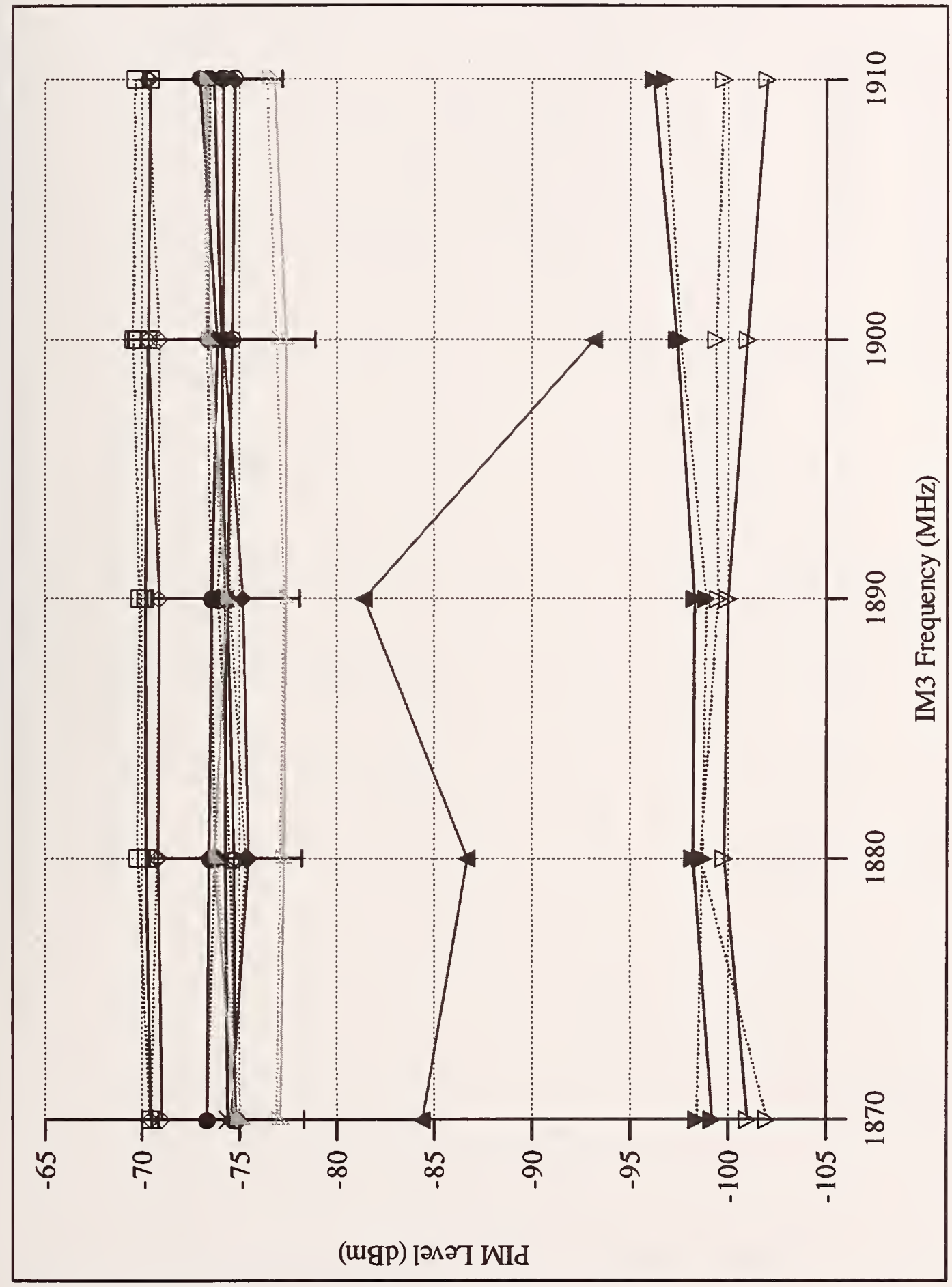

ป 

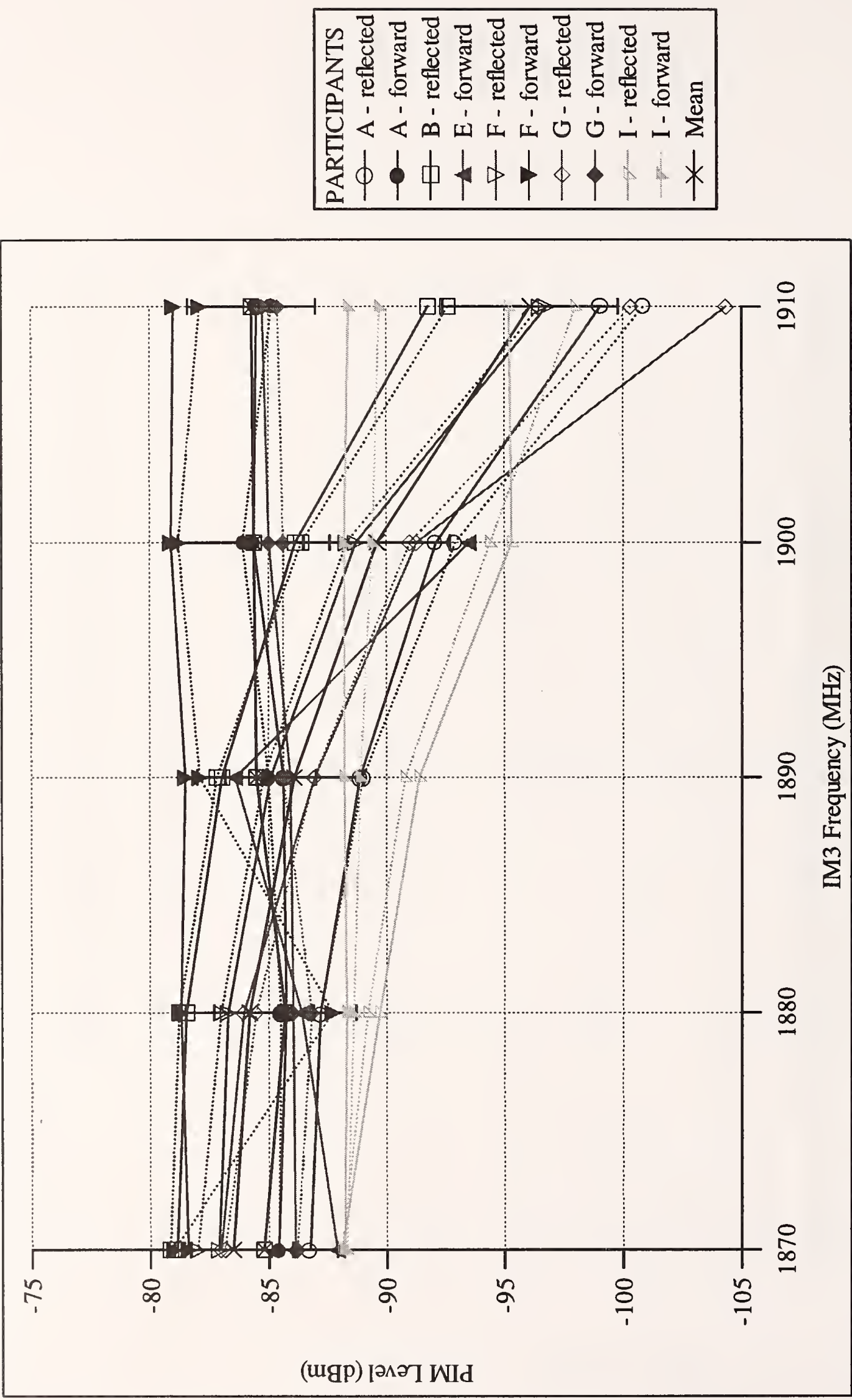

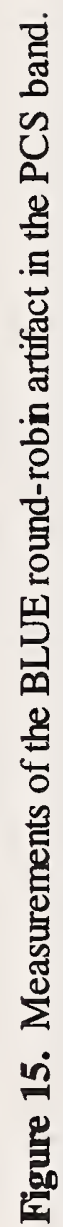



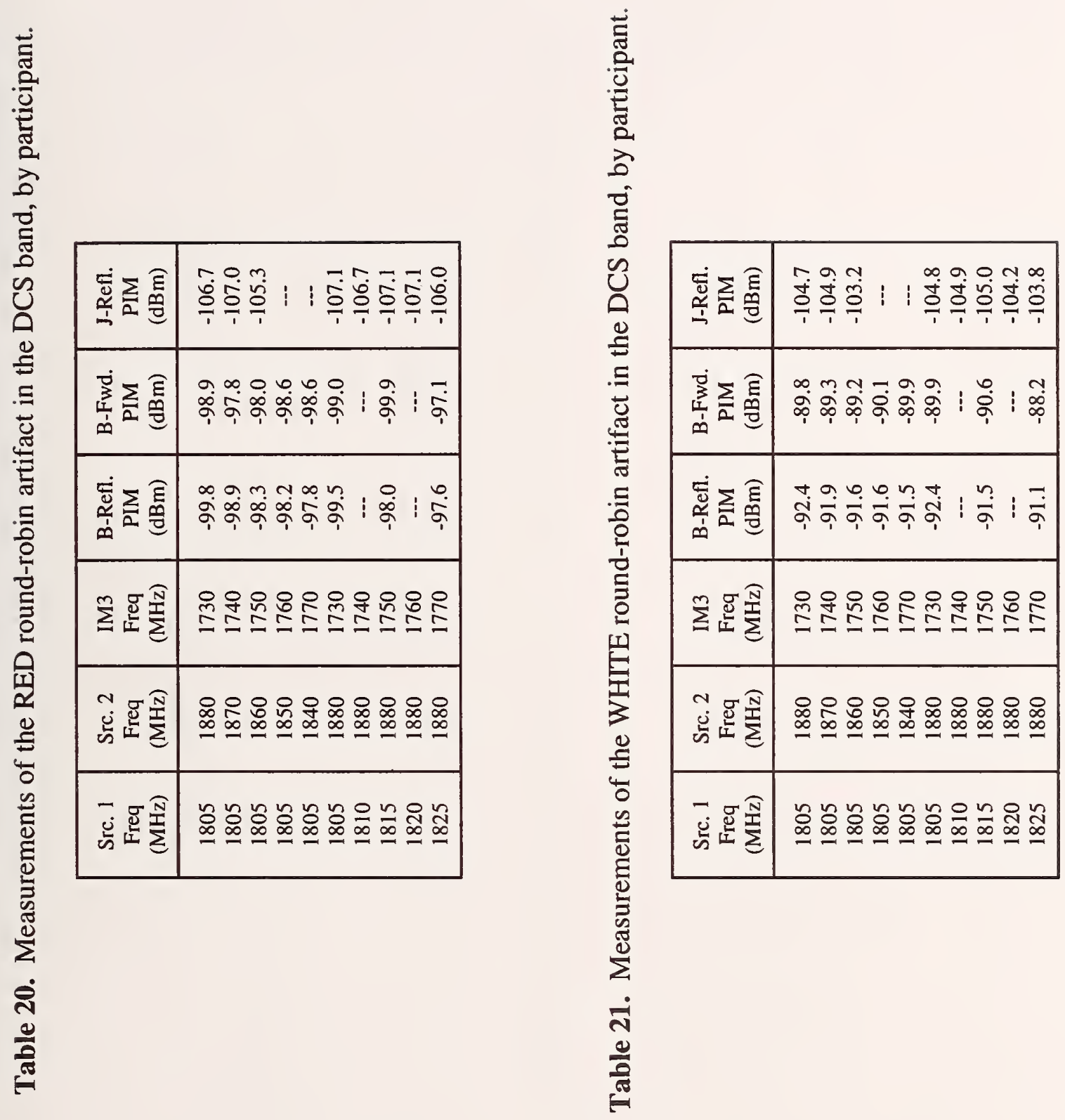


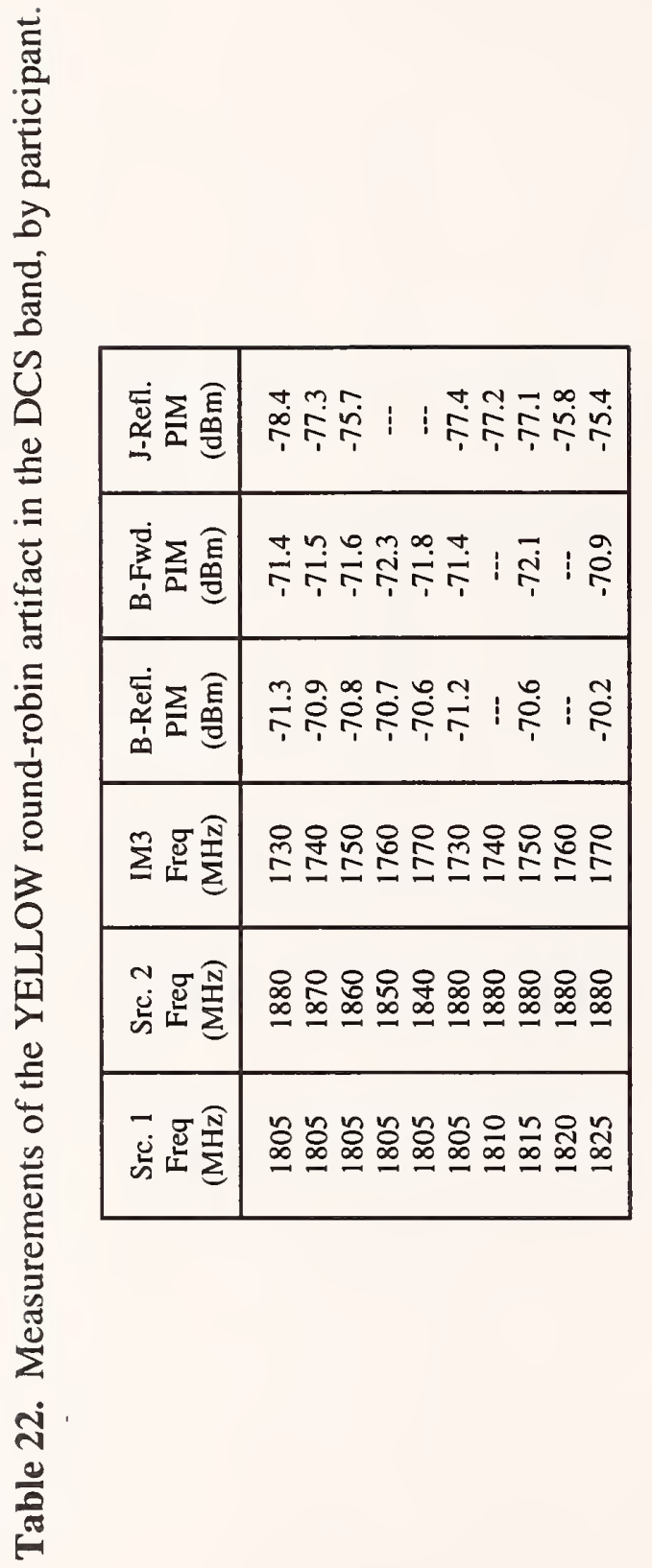

ปี 

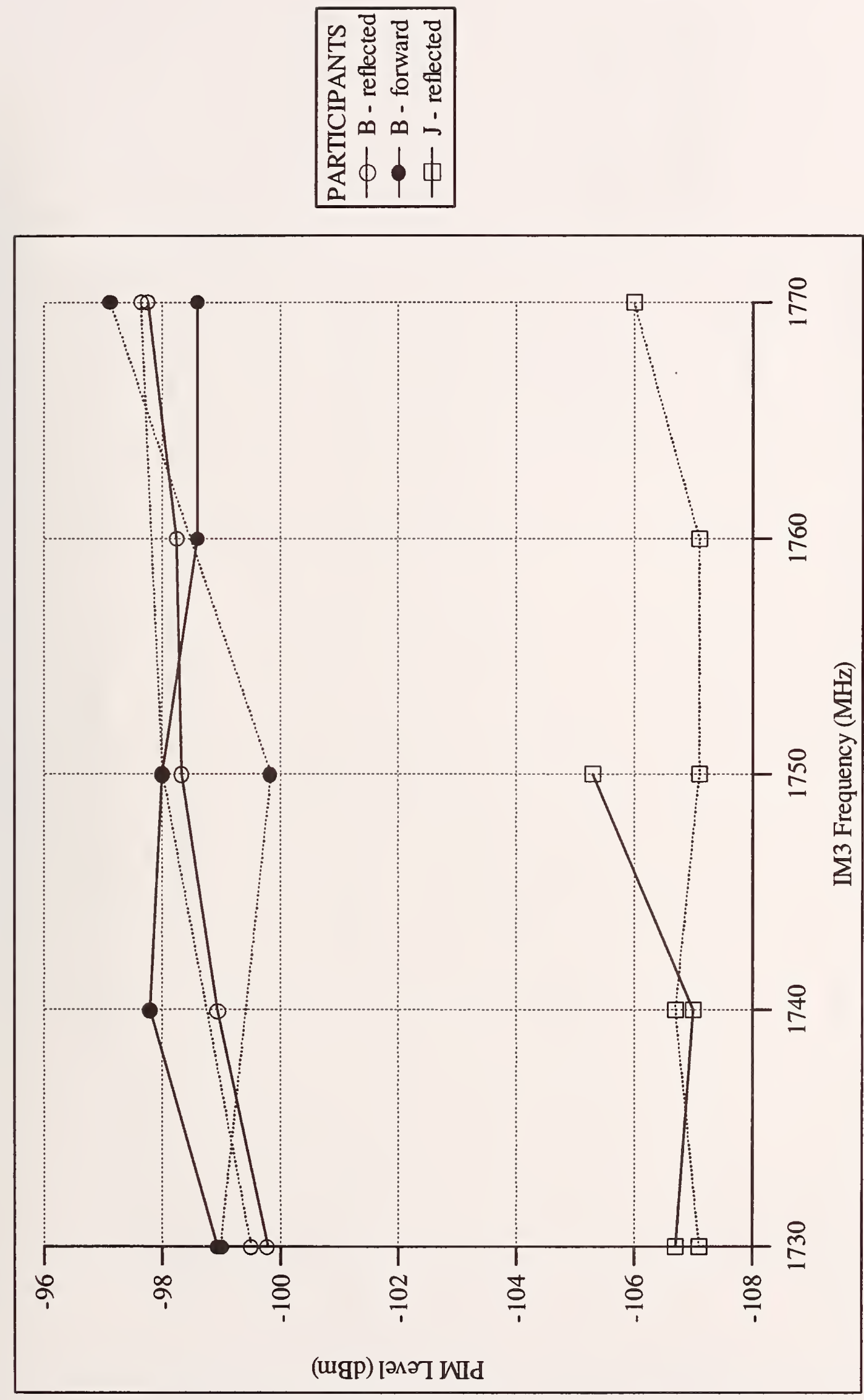

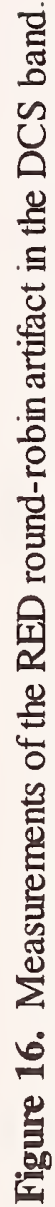



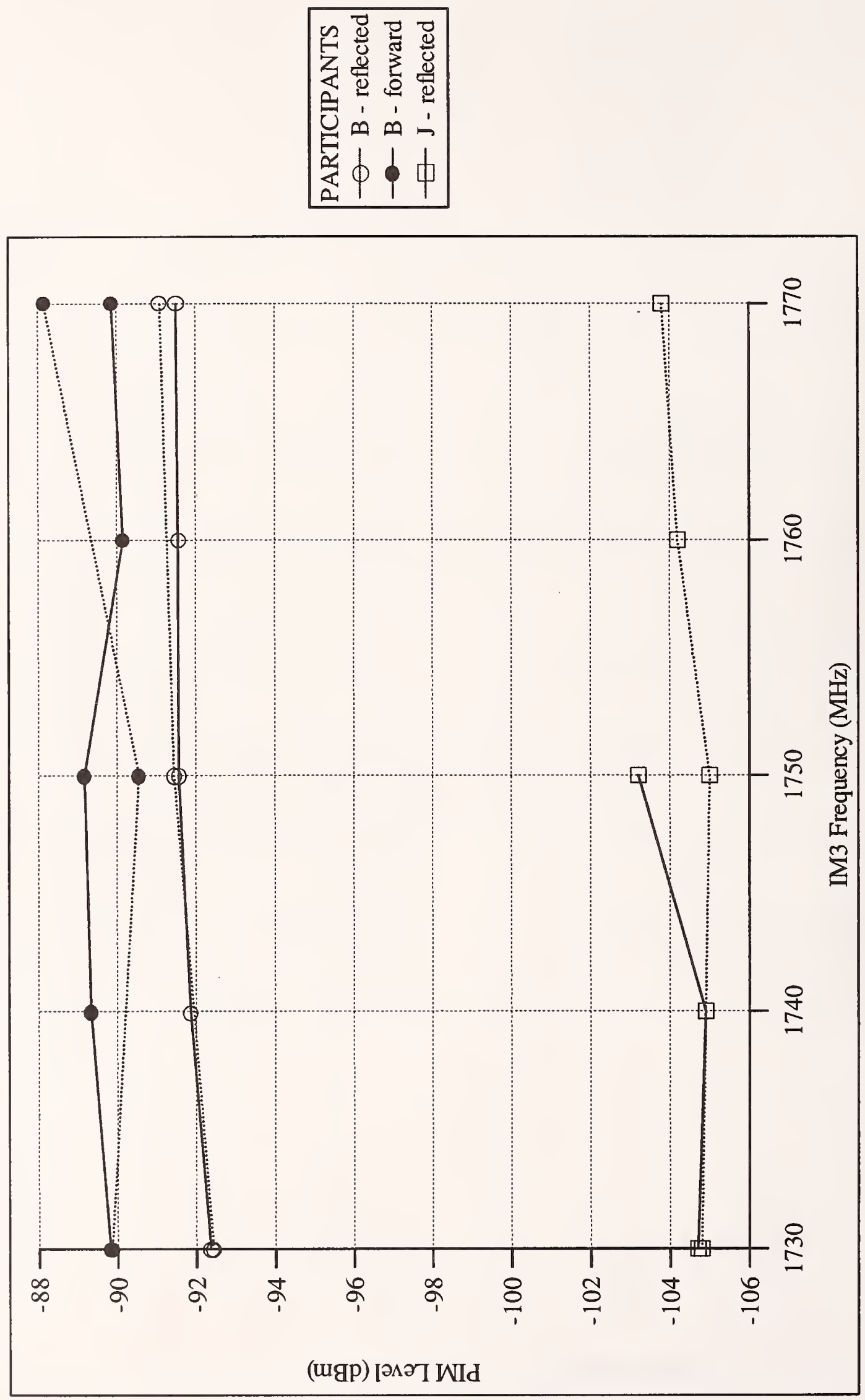


\begin{tabular}{|c|}
\hline 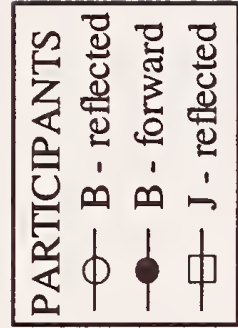 \\
\hline
\end{tabular}

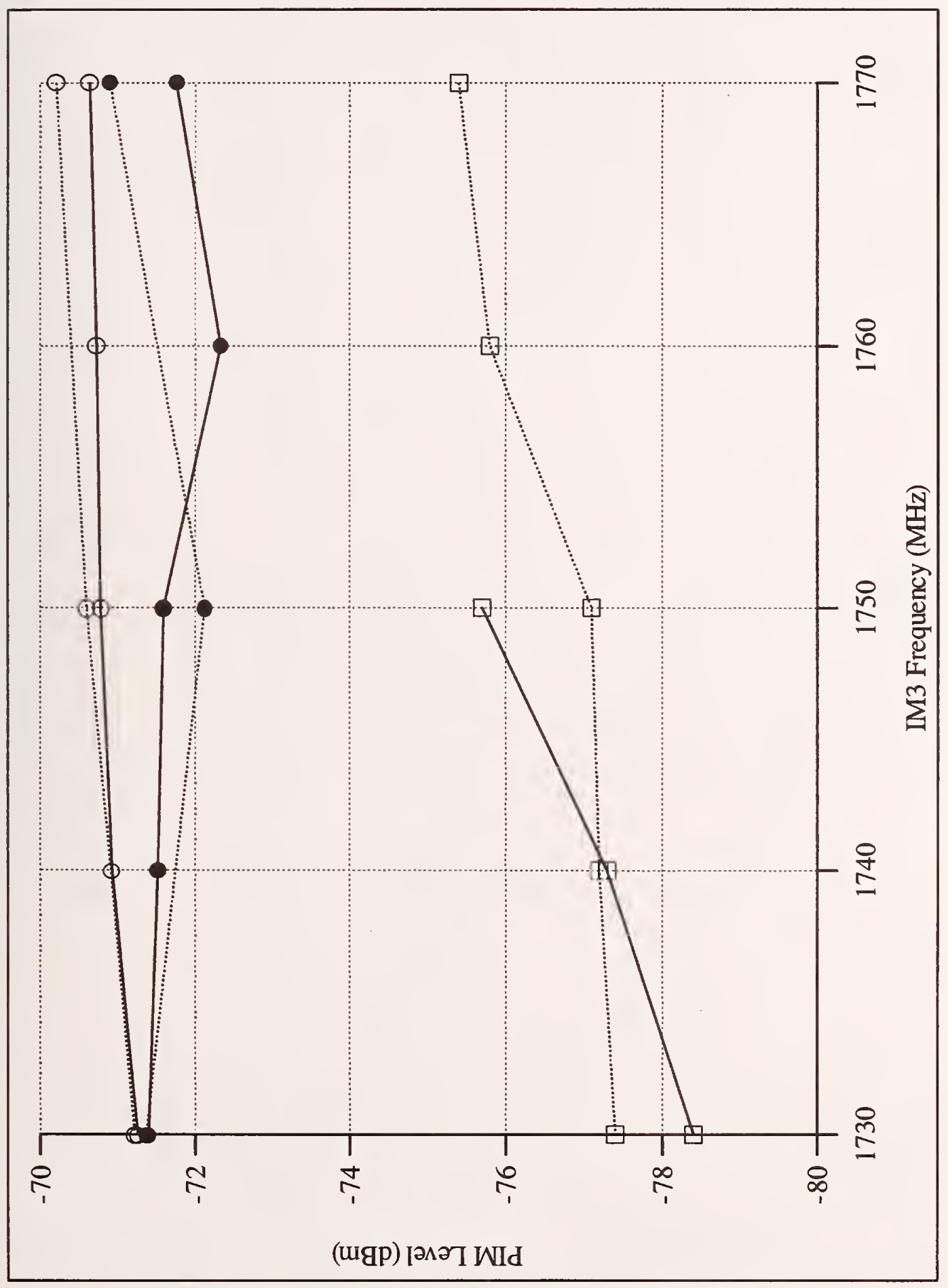

完 

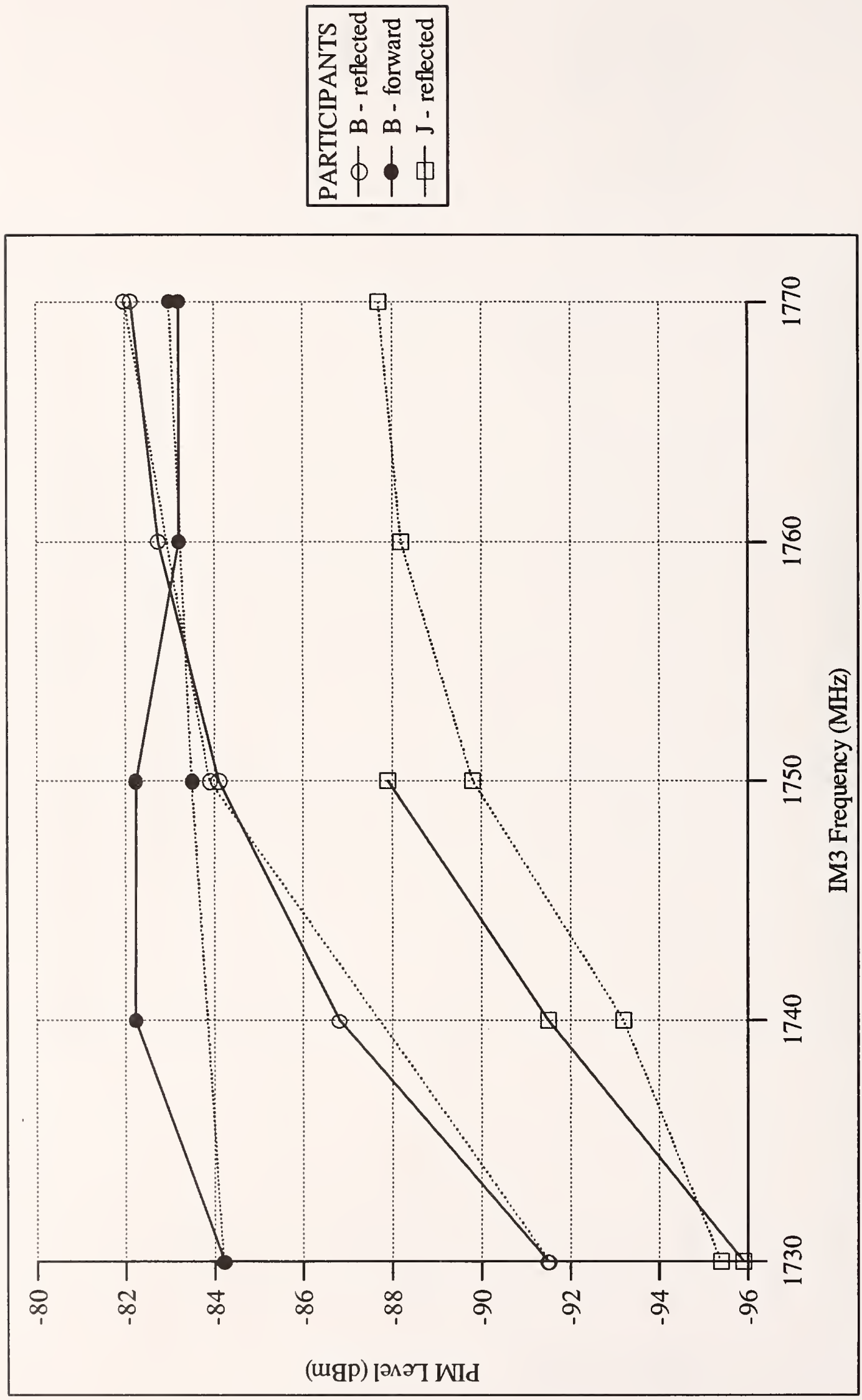

व્ठ 

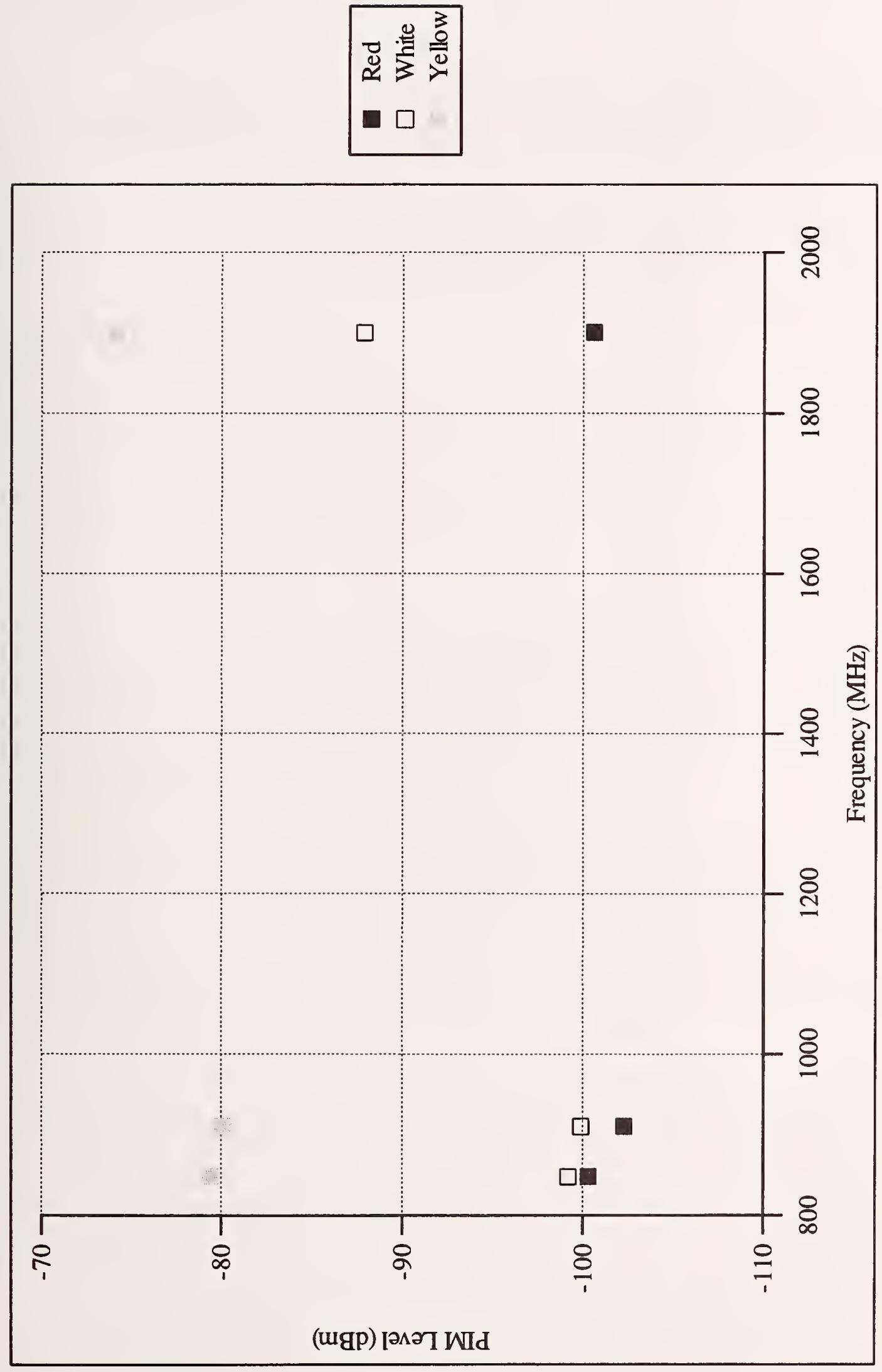

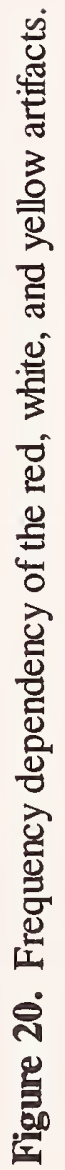




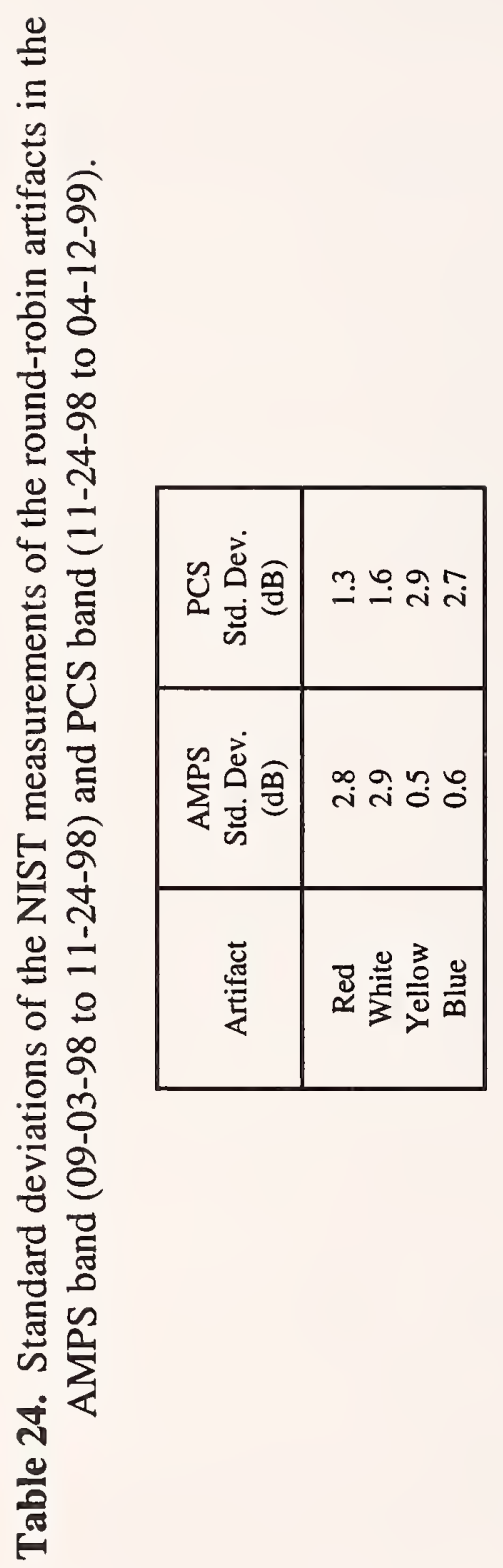




\section{NIST Passive Intermodulation Measurement Comparison for Wireless Base-Station Equipment}

\section{Instructions for Participants}

\section{Round-Robin Artifacts}

You will find enclosed four two-port artifacts with DIN 7-16 connectors and varying levels of passive nonlinearity to be measured. Please make every effort to perform all of the measurements described below, and to send the artifacts along with the data, back to NIST within one calendar week after receiving them. If for some reason your laboratory cannot meet this deadline, contact us immediately so we can make alternative arrangements.

\section{Measurements}

The power of the third-order intermodulation products of each round-robin artifact are to be measured in a system with two cw signal sources, following the International Electrotechnical Commission's guidelines (IEC Technical Committee 46, Working Group 6). The two test signals should each measure $+43 \mathrm{dBm}(20 \mathrm{~W})$ at the test ports of your measurement system. All measurements should be reported in $\mathrm{dBm}$.

The third-order intermodulation products of each artifact are to be measured within the receive (uplink) band of any or all of the communication bands listed below when the two $+43 \mathrm{dBm}$ signals are tuned to fall within the corresponding transmit (down-link) band. The minimum required data is a single third-order intermodulation power in one communication band. If your system has the ability to make swept frequency measurements, please perform additional measurements at the frequencies listed on the attached Artifact Measurement Forms. In either case, please provide an overall intermodulation value for the entire band in the space provided.

Measure either or both forward and reflected intermodulation products. To measure reflected intermodulation, connect the male connector of the artifact to the active test port of your system and the female connector of the artifact to a low passive intermodulation load. To measure forward intermodulation, connect the male connector of the artifact to the active test port of your system and the female connector of the artifact to your own cable that is in turn connected to the receiving port of your system. 
If your system has the capability of measuring intermodulation products in more than one communication band, or if you have multiple systems, we encourage you to measure the devices in as many of the different bands as possible.

\begin{tabular}{|c|c|c|}
\hline Communication band & $\begin{array}{c}\text { Receive frequencies } \\
\text { (up-link) } \\
\text { (MHz) }\end{array}$ & $\begin{array}{c}\text { Transmit frequencies } \\
\text { (down-link) } \\
\text { (MHz) }\end{array}$ \\
\hline AMPS & $824-849$ & $869-894$ \\
PCS 1900 & $1850-1910$ & $1930-1990$ \\
GSM & $890-915$ & $935-960$ \\
DCS 1800 & $1710-1785$ & $1805-1880$ \\
\hline
\end{tabular}

\title{
Reporting the Results
}

When you have finished your measurements, enter your measured data (in $\mathrm{dBm}$ ) of each artifact into the provided Artifact Measurement Forms replacing the zeroes with your data. Where you do not make measurements, do not replace the zeroes. For each artifact, use a separate form. On the form, enter the artifact color, as painted on the device, along with contact information, and any comments you would like to share with us relating to your measurements, such as environmental conditions, measurement system and load used, uncertainty bounds, and anything else you think appropriate.

\section{Returning the Devices}

Once you have completed the Artifact Measurement Forms for each of the measured artifacts, e-mail them to jiargon@ nist.gov, and return the devices with hard copies of the data to:

\author{
NIST c/o Paula Hewitt \\ 325 Broadway, Mail Stop 813, Boulder, CO 80303
}

\section{Contact Information}

If you have any questions regarding these measurements, contact:

$$
\begin{gathered}
\text { Jeffrey Jargon } \\
\text { National Institute of Standards and Technology } \\
\text { 325 Broadway, Mail Stop } 813.01
\end{gathered}
$$

Tel: (303)497-3596 | Fax: (303)497-3970 | E-Mail: jjargon@ nist.gov

Thank you for your participation. We will contact you in the near future showing you how your measurements compared with everybody elses', keeping other companies' identities confidential. Likewise, your identity will remain confidential in the reports we send to other companies. 


\section{Appendix B. Artifact Measurement Form}

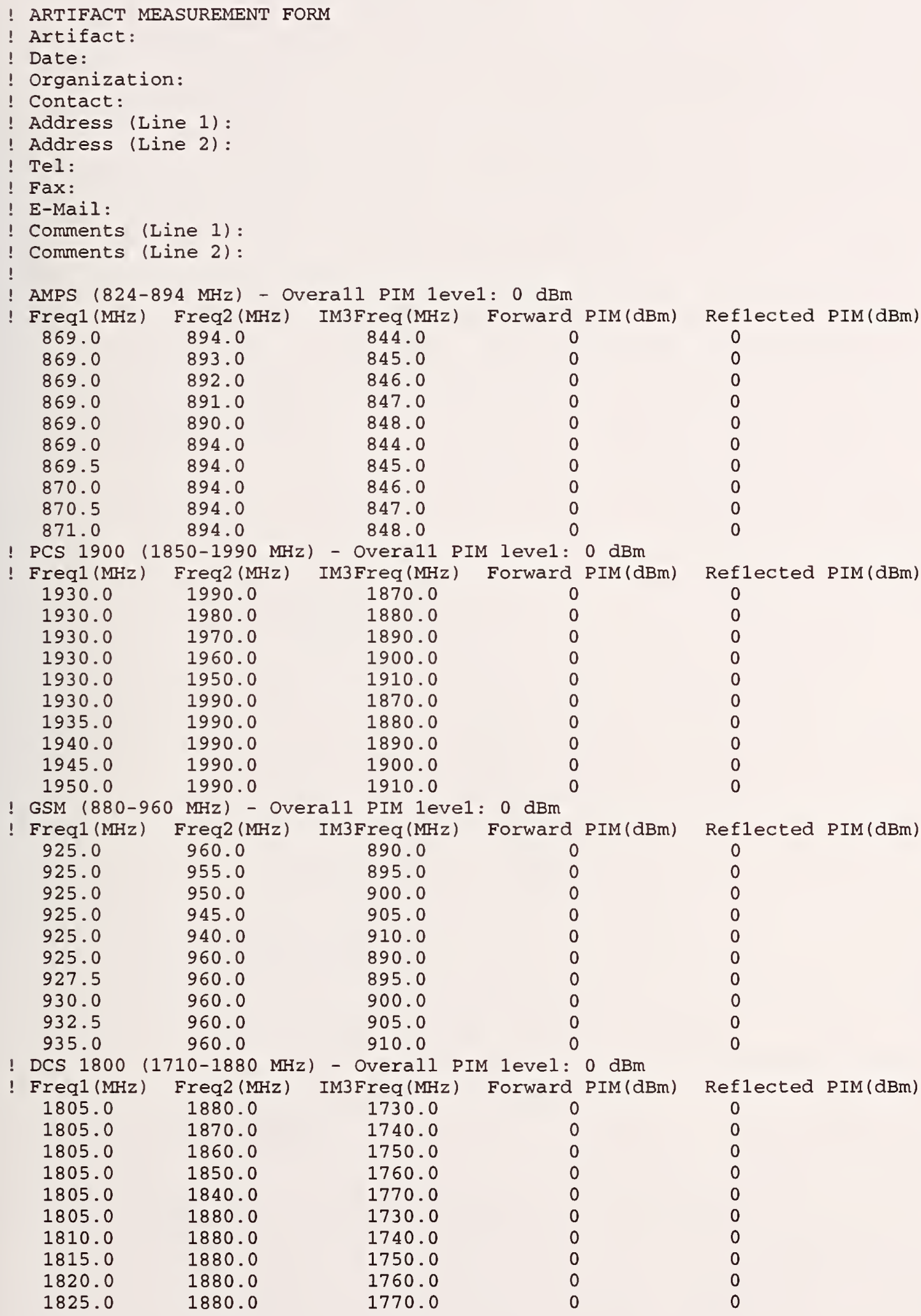





\section{Periodical}

Journal of Research of the National Institute of Standards and Technology-Reports NIST research and development in those disciplines of the physical and engineering sciences in which the Institute is active. These include physics, chemistry, engineering, mathematics, and computer sciences. Papers cover a broad range of subjects, with major emphasis on measurement methodology and the basic technology underlying standardization. Also included from time to time are survey articles on topics closely related to the Institute's technical and scientific programs. Issued six times a year.

\section{Nonperiodicals}

Monographs-Major contributions to the technical literature on various subjects related to the Institute's scientific and technical activities.

Handbooks-Recommended codes of engineering and industrial practice (including safety codes) developed in cooperation with interested industries, professional organizations, and regulatory bodies.

Special Publications-Include proceedings of conferences sponsored by NIST, NIST annual reports, and other special publications appropriate to this grouping such as wall charts, pocket cards, and bibliographies.

Applied Mathematics Series-Mathematical tables, manuals, and studies of special interest to physicists, engineers, chemists, biologists, mathematicians, computer programmers, and others engaged in scientific and technical work.

National Standard Reference Data Series-Provides quantitative data on the physical and chemical properties of materials, compiled from the world's literature and critically evaluated. Developed under a worldwide program coordinated by NIST under the authority of the National Standard Data Act (Public Law 90-396). NOTE: The Journal of Physical and Chemical Reference Data (JPCRD) is published bimonthly for NIST by the American Chemical Society (ACS) and the American Institute of Physics (AIP). Subscriptions, reprints, and supplements are available from ACS, 1155 Sixteenth St., NW, Washington, DC 20056.

Building Science Series-Disseminates technical information developed at the Institute on building materials, components, systems, and whole structures. The series presents research results, test methods, and performance criteria related to the structural and environmental functions and the durability and safety characteristics of building elements and systems.

Technical Notes-Studies or reports which are complete in themselves but restrictive in their treatment of a subject. Analogous to monographs but not so comprehensive in scope or definitive in treatment of the subject area. Often serve as a vehicle for final reports of work performed at NIST under the sponsorship of other government agencies.

Voluntary Product Standards-Developed under procedures published by the Department of Commerce in Part 10, Title 15, of the Code of Federal Regulations. The standards establish nationally recognized requirements for products, and provide all concerned interests with a basis for common understanding of the characteristics of the products. NIST administers this program in support of the efforts of privatesector standardizing organizations.

Consumer Information Series-Practical information, based on NIST research and experience, covering areas of interest to the consumer. Easily understandable language and illustrations provide useful background knowledge for shopping in today's technological marketplace.

Order the above NIST publications from: Superintendent of Documents, Government Printing Office, Washington, DC 20402.

Order the following NIST publications-FIPS and NISTIRs-from the National Technical Information Service, Springfield, VA 22161.

Federal Information Processing Standards Publications (FIPS PUB)-Publications in this series collectively constitute the Federal Information Processing Standards Register. The Register serves as the official source of information in the Federal Government regarding standards issued by NIST pursuant to the Federal Property and Administrative Services Act of 1949 as amended, Public Law 89-306 (79 Stat. 1127), and as implemented by Executive Order 11717 (38 FR 12315, dated May 11, 1973) and Part 6 of Title 15 CFR (Code of Federal Regulations).

NIST Interagency Reports (NISTIR)-A special series of interim or final reports on work performed by NIST for outside sponsors (both government and non-government). In general, initial distribution is handled by the sponsor; public distribution is by the National Technical Information Service, Springfield, VA 22161, in paper copy or microfiche form. 
U.S. Department of Commerce

National Institute of Standards and Technology

325 Broadway

Boulder, Colorado 80303-3328

Official Business

Penalty for Private Use, $\$ 300$ 